Dialectologia. Special issue, IX (2021), 151-192.

ISSN: 2013-2247

Received 8 February 2021.

Accepted 21 February 2021.

\title{
LA FRASEOLOGÍA CON VERBOS DE MOVIMIENTO EN EL ALPI: \\ ACERCA DE LLEVAR A CUESTAS ${ }^{1}$
}

Jacinto GonZÁlez CoBAS

Universidad Autónoma de Madrid*

jacinto.gonzalez@uam.es

\section{Resumen}

Este artículo parte de las variantes registradas en el ALPI a propósito de la locución llevar a cuestas. Muchas de ellas no presentan documentación alguna en los corpus utilizados en esta investigación (COSER, CORPES XXI y Corpus del Español) ni en el buscador Google; otras de ellas están atestiguadas únicamente en repertorios lexicográficos y en trabajos de índole científica y académica; hay un tercer grupo de unidades fraseológicas que figuran en textos de carácter no especializado. Asimismo algunas de ellas encuentran reflejo en el Diccionario de la lengua española (DLE) de la RAE; no así la gran mayoría. Se aportan posibles explicaciones a estos hechos y se concluye que la fraseología es uno de los exponentes más claros de variación diacrónica y diatópica.

\section{Palabras clave}

$A L P I, C O S E R$, fraseología, llevar a cuestas, verbos de movimiento

\footnotetext{
${ }^{1}$ Este trabajo ha sido realizado en el marco del proyecto PGC2018-095077-B-C42, dirigido por Inés Fernández-Ordóñez y Ana Serradilla Castaño: Cambios en el habla rural: del siglo xx (Atlas Lingüístico de la Península Ibérica, ALPI) al siglo XXI (Corpus Oral y Sonoro del Español Rural, COSER).

* Departamento de Filología Española, Facultad de Filosofía y Letras, Universidad Autónoma de Madrid. Calle C/ Tomás y Valiente 1. 28049 Madrid.
} 


\section{PHRASEOLOGY WITH VERBS OF MOVEMENT IN THE ALPI: LLEVAR A CUESTAS}

\section{Abstract}

This paper presents a corpus study of the phrase llevar a cuestas and its variants. An initial list of variants of this phrase was obtained from the ALPI. These variants were then searched for in a number of corpora (COSER, CORPES XXI, Corpus del Español and Google). The study showed that many of the variants from the ALPI list were not present in any of the corpora. Others are just found only in lexicographic repertoires and in scientific and academic works. A third group of phraseological units was found to appear only in non-specialized texts. In addition, only a minimal part of the expressions appears in the Diccionario de la lengua española $(D L E)$ by the RAE. This paper provides possible explanations for the findings of the study and concludes that phraseology is one of the clearest exponents of diachronic and diatopic variation.

\section{Keywords}

$A L P I, C O S E R$, phraseology, llevar a cuestas, verbs of movement

\section{Introducción}

En este trabajo vamos a estudiar la presencia de llevar a cuestas y sus variantes en el español rural. Hemos seleccionado esta locución de entre las tres únicas unidades fraseológicas (UF) con verbos de movimiento ${ }^{2}$ incluidas en el ALPI (andar a gatas, caer de bruces y llevar a cuestas) y hemos rastreado su presencia en el COSER para observar las variantes que aún siguen vivas en el español rural. Nuestro objetivo es analizar hasta qué punto perviven expresiones que formaban parte del habla de muchos pueblos españoles en la primera mitad del siglo XX. Para ello, prestaremos atención también a otros corpus como el CORPES XXI o el Corpus del Español de Davies y nos serviremos del buscador Google.

Antes de comenzar nuestro análisis, queremos destacar la importancia de dos corpus que resultan imprescindibles para el conocimiento de la realidad diatópica del español.

Como se recoge en la página web del ALPI (http://alpi.csic.es/es/alpi/valorhistorico):

\footnotetext{
${ }^{2}$ Vid. González Cobas \& Serradilla Castaño (2013) para acceder a una propuesta lexicográfica acerca de las unidades fraseológicas construidas con verbos de movimiento.
} 
A pesar del tiempo transcurrido y de la publicación de los atlas regionales, el valor científico del ALPI sigue siendo indudable, entre otras cosas porque la península Ibérica carece hasta ahora de un atlas general semejante a los que poseen otros grandes dominios lingüísticos europeos, un atlas de referencia con el que poder contrastar los datos recogidos con posterioridad en las mismas zonas, y cuyos materiales permiten, además, el estudio comparado de las hablas iberorrománicas. Es cierto que desde los años en los que se hizo el grueso de sus encuestas las variedades lingüísticas peninsulares han evolucionado y, sobre todo, las condiciones demográficas y sociales son muy diferentes de las que reflejan los datos del ALPI, pero precisamente por eso resulta evidente que el paso del tiempo no ha devaluado los contenidos de este atlas, sino que los ha convertido en documentación lingüística y etnográfica, de ahí su interés científico.

Efectivamente, contar con datos como estos, obtenidos en los años 30 del siglo $\mathrm{XX}$, nos va a permitir sentar las bases para conocer el uso de determinadas locuciones en la lengua rural de la Península.

Por su parte, Inés Fernández-Ordóñez (2007: 31), directora del COSER, alude a una de las características diferenciadoras de este corpus que puede resultarnos especialmente útil para nuestros objetivos:

El hecho de que la mayor parte de los corpus orales del español se nutran de fuentes como los medios de comunicación proporciona cierta singularidad al COSER, ya que muy rara vez los hablantes entrevistados para el COSER aparecen registrados en ese ámbito. La comparación entre los datos obtenidos en el COSER y en otros corpus de español hablado permite, pues, hacer explícitas diferencias socioculturales. En este aspecto el COSER se ha revelado especialmente útil, pues facilita el estudio de las soluciones no-estándar, las cuales suelen ser sistemáticamente evitadas en la lengua escrita y en el habla de los grupos socioculturales de mayor educación.

A lo largo de este trabajo nos centraremos en el análisis de los datos procedentes de los corpus, pero antes nos detendremos en el concepto de unidad fraseológica y prestaremos atención a sus características sintácticas y semánticas.

Termina este estudio con unas reflexiones en torno a la pervivencia de llevar a cuestas y sus variantes en el español actual, y también acerca de cómo el estudio de la 
fraseología puede permitirnos avanzar en el conocimiento de la evolución del idioma desde las perspectivas diacrónica y diatópica.

\section{El concepto de unidad fraseológica y sus características formales y semánticas}

Antes de adentrarnos en el análisis de nuestro corpus, consideramos fundamental aludir a los requisitos necesarios para que una expresión sea considerada locución. Parece haber unanimidad entre los investigadores en que en todos los casos debe existir pluriverbalidad: a cuestas, llevar a cuestas y todas las variantes que mencionaremos cumplen este criterio.

Por otro lado, son expresiones con una alta frecuencia de uso. Se trata de un requisito que también cumple la locución analizada en este trabajo, como lo demuestra no solo su presencia en los corpus, sino el hecho de que en Google hay 6060000 resultados de a cuestas y 3500000 de llevar a cuestas. ${ }^{3}$

Dentro de las características que permiten definir las locuciones, se incluye también la institucionalización o reproducibilidad que, siguiendo a Simó (2017: 116), "remite al proceso por el cual una expresión neológica pasa a convertirse en un elemento propio del acervo lingüístico y cultural de una comunidad lingüística debido a su repetición y uso". La locución que aquí analizamos presenta un significado literal, pero este convive con nuevos significados a los que se llega mediante una serie de procesos metafóricos o metonímicos: puede llevarse a alguien o a algo literalmente a cuestas con un movimiento real o puede llevarse un problema, un dolor, un recuerdo... donde el movimiento es figurado. Asimismo, la metonimia entra en juego en el sentido de que se toma una parte por el todo (las "cuestas" o costillas, hombros, espaldas... sirven para referirnos al modo de llevar a alguien o a algo).

\footnotetext{
${ }^{3}$ Estos datos corresponden a una búsqueda realizada el 13 de septiembre de 2020.
} 
Otro requisito al que siempre se alude al hablar de unidades fraseológicas es el de la fijación; este concepto ha de ser analizado junto al de la variación, que diversos investigadores ${ }^{4}$ consideran una característica definitoria de las unidades fraseológicas.

Acudimos de nuevo a Simó (2017: 118-119) para referirnos a los diversos tipos de variación con los que nos podemos encontrar en el caso de las locuciones:

Han sido diversos los tipos de variación descritos por los teóricos (gráfica, fónica, morfológica, léxica, sintáctica, etc.), si bien entre todos ellos existe un consenso bastante generalizado a la hora de separar lo que, comúnmente, se han denominado variantes de variaciones. Las primeras responden a cambios previstos, codificados y fijados de antemano, es decir, autorizados (García-Page 2008: 217). En este conjunto cabrían las llamadas variantes en sentido estricto de Zuluaga $(1975,1980)$, esto es, aquellas UFs equivalentes que cumpliesen los siguientes requisitos: darse en una misma lengua funcional, ser fijas y sinónimas, libres e independientes de los contextos y poseer una estructura y unos componentes similares: alzarse/cargar con el santo y la limosna. Corpas (1996) [...]. Según ella, constituyen variantes no solo las unidades mencionadas, sino también aquellas en las que se modifica alguna preposición (irse de/a picos pardos), un artículo (irse a tomar por (el) saco) o el número (a pie/pies juntillas) y el orden de constituyentes (yo qué se / qué sé yo). Asimismo, contempla como variantes las UFs acortadas (por orden ( $y$ gracia) de). Por último, identifica variantes en estructuras que difieren en un componente cuya semántica es parcialmente idéntica (todo queda en casa/familia).

Las variaciones responden a cambios efectuados por derivación (meter la pata - metedura de pata), a UFs opuestas dentro de una serie (cabeza arriba / cabeza abajo) o procedentes de distintas variedades diatópicas (hacer novillos hacer vaca) o diafásicas (irse a tomar por (el) saco - irse a tomar viento).

En nuestro corpus, según la clasificación de Simó (2017), aparecen variantes de algunos de los tipos mencionados:

1. Variantes en sentido estricto: llevar a cuestas, llevar a caballo, llevar a las espaldas.

2. Variantes con modificación en el uso de la preposición: a cuestas, en cuestas; en la presencia o ausencia de artículo: a cuestas, a las cuestas; o en el número: a costilla, a costillas.

\footnotetext{
${ }^{4}$ Entre ellos, Ortega Ojeda \& González Aguiar (2005: 92), quienes definen la variación fraseológica como "el fenómeno que se produce cuando una UF, a pesar de estar fijada, se materializa en "formas distintas» sin que dicho cambio conlleve alteraciones en el significado fraseológico".
} 
3. Variantes con componentes similares semánticamente: a costillas, a cuestas, a costillinas.

4. Asimismo, hay multitud de variantes procedentes de distintas variedades diatópicas: llevar a recachas, a la pela. ${ }^{5}$

Como puede observarse, la fijación no implica que no sea posible cierta variación.

Otro requisito que debe cumplir una locución es, como se señala en Serradilla Castaño (2019: 189), la idiomaticidad, el valor figurado o, lo que es lo mismo, un nuevo significado que no es deducible de la suma de los significados de los elementos que la integran, sino al que se llega a través de diversos procesos metafóricos o metonímicos. En expresiones como llevar a caballo, a cuestas, a costilla entran en juego dichos procesos. En nuestro caso se trata de locuciones con un mínimo grado de opacidad, en el sentido de que, como señalaba Timofeeva (2008: 333): “A partir de la asunción de que el significado de una expresión idiomática no se deduce de la suma de los significados de sus partes, se observa que no todas las UFs poseen el mismo grado de idiomaticidad y en muchas de ellas podemos «adivinar» el significado de la expresión total recurriendo a nuestros conocimientos extralingüísticos y culturales". Dado que conocemos el significado de términos como llevar, hombros, espaldas, costillas... nos resulta transparente el significado de las locuciones, aunque estén presentes ciertos cambios provocados por la metáfora y la metonimia. Más opacas nos resultan aquellas compuestas por términos que no forman parte de la lengua general, lo que nos obliga a interpretarlas a través del contexto o de diccionarios regionales específicos (llevar a recachas, a la esquena, a repatajones).

El cumplimiento de estos criterios nos permite incluir las expresiones analizadas dentro de la categoría de las locuciones: locución adverbial en el caso de a cuestas y sus variantes o locución verbal si consideramos que llevar constituye una parte fundamental de la estructura llevar a cuestas. Desde esta perspectiva, el verbo de movimiento se convierte en un elemento constitutivo, dado que la locución adverbial

\footnotetext{
${ }^{5}$ Estas podrían considerarse también variantes en sentido estricto, en cuanto que aparecen en la misma lengua y son fijas y sinónimas. Si se clasifican en este grupo, es simplemente porque se pone el foco en la variedad diatópica.
} 
precisa de él para funcionar en una oración, al tiempo que se trata del verbo que de forma mayoritaria se combina con ella. Apoyan esta afirmación las palabras de Simó (2017: 308): “concebimos la fraseología como un fenómeno construccional que radica en el verbo y en sus propiedades combinatorias sintáctico-semánticas". De todas formas, el conflicto no está tanto entre la locución adverbial y la verbal, sino entre la colocación compleja verbo + locución adverbial y la locución verbal tradicional. En esta línea, Simó (2017) sigue a García-Page (2013: 484), quien afirma que el grado de coaparición frecuente entre verbo y sintagma es un factor definitorio de la categoría en cuestión; y así, la restricción absoluta de un verbo y un sintagma preposicional haría que nos inclináramos hacia la etiqueta de locución, mientras que la amplitud combinatoria verbal nos orientaría hacia la de colocación compleja. De acuerdo con esta argumentación, se podría hablar de locución verbal en el caso que nos ocupa, aunque somos conscientes de que las fronteras no son siempre nítidas entre una y otra construcción. ${ }^{6}$

En cuanto a la estructura formal de las locuciones analizadas, es casi siempre similar y predomina la constituida por $(\mathrm{V})+$ prep. + (art.) + sust., esquema en el que concretamente la preposición a y los nombres en femenino plural adquieren protagonismo: a burras, (llevar) a cuestas, a costillas, a la esquena, (llevar) a las espaldas, al cordero, al cuadril, en cabrito; aunque también hay algunos casos menos frecuentes de (V) + sust. Ilevar cuestas, de (V) + part. llevar escarrapachado o (V) + prep. + prep. + sust. llevar a en coquetas, a en culecas. Todos ellos exigen un complemento directo que haga referencia a la persona o cosa que se traslada o que supone un esfuerzo para el sujeto.

A continuación, trataremos de forma más pormenorizada las distintas variantes que aparecen en los corpus analizados.

\footnotetext{
${ }^{6}$ Vid. Serradilla Castaño (2019: 184-185) para profundizar en este punto.
} 


\section{Llevar a cuestas y sus variantes en el ALPI}

La pregunta 751 del $A L P I$ indaga sobre la expresión llevar a cuestas, de la que hay hasta 157 variantes $^{7}$ entre 576 respuestas, siempre con el verbo llevar, salvo un caso en Peñas de San Pedro (Albacete), en el que se usa el verbo echar (echar en cuestas). Puede observarse, como hemos avanzado, la importancia del verbo a la hora de constituir la locución.

Se muestra a continuación una tabla en la que figuran todas las variantes localizadas en el $A L P I$ :

\begin{tabular}{|c|c|c|c|c|c|c|}
\hline & a colletes & a cuestas & $\begin{array}{l}\text { a las } \\
\text { costillas }\end{array}$ & a rexolinas & cuestas & en trucha \\
\hline aceite & a conches & a cuestes & a las cuestas & a ricotes & culleca & en truncha \\
\hline a aceite & a concos & a cullacas & $\begin{array}{l}\text { a las } \\
\text { espaldas }\end{array}$ & a sarrajitos & $\begin{array}{l}\text { echar en } \\
\text { cuestas }\end{array}$ & en trunchas \\
\hline a ambé & a cones & a curumbillo & a loilos & a xocastrinas & embá & en trunche \\
\hline a borriquitos & a coscaletas & a cuscaletas & a marchante & al arre & en cabrito & escamarrau \\
\hline a burras & a coscoletas & a as costillas & a memé & al chin & en carilota & escarrapachado \\
\hline a burro & $\begin{array}{l}\text { a } \\
\text { cosqueretas }\end{array}$ & a en colicas & $\begin{array}{l}\text { a } \\
\text { patarrajones }\end{array}$ & al chin chin & en clavito & h.arriquín \\
\hline a caballico & a costaletas & a en coquetas & a perejetes & al chinchín & $\begin{array}{l}\text { en } \\
\text { coquetas }\end{array}$ & $\begin{array}{l}\text { I.levar a } \\
\text { recachas }\end{array}$ \\
\hline a caballo & a costas & a en culecas & a quetas & al chinchu & $\begin{array}{l}\text { en } \\
\text { corderetas }\end{array}$ & $\begin{array}{l}\text { I.levar a } \\
\text { recostines }\end{array}$ \\
\hline a caballu & a costetas & $\begin{array}{l}\text { a } \\
\text { escarramanchón }\end{array}$ & a rajetos & al chulchi & $\begin{array}{l}\text { en } \\
\text { corderetes }\end{array}$ & levar as costa \\
\hline a cabrito & a costiellas & a jitas & a recachu & al churchi & en corderos & levar as costas \\
\hline a cachón & a costilla & a la carga leña & a recocho & al cordero & $\begin{array}{l}\text { en } \\
\text { coscoletas }\end{array}$ & $\begin{array}{l}\text { levar ás } \\
\text { garabitolas }\end{array}$ \\
\hline $\begin{array}{l}\text { a } \\
\text { carrapachón }\end{array}$ & a costillas & a la chin & a la rica & al cuadril & en cotenas & levar o carrelo \\
\hline a carrapotu & a costillinas & a la costilla & a recotas & al cuairí & en cotines & $\begin{array}{l}\text { llevallo as } \\
\text { costas }\end{array}$ \\
\hline a carricotes & a costinas & a la espalda & a recuestas & al cuello & $\begin{array}{l}\text { en as } \\
\text { costilla }\end{array}$ & Ilevarlu aceite \\
\hline $\begin{array}{l}\text { a } \\
\text { carrinchoncha }\end{array}$ & a costrinas & a la esquena & a rejetas & al hombru & $\begin{array}{l}\text { en as } \\
\text { costillas }\end{array}$ & montado \\
\hline a carriquicho & a cotenas & a la pela & a rejín & al jarrique & en crabito & o riquichu \\
\hline a chinchín & a cotetas & a la recacha & a rejito & al oilo & en cucú & rejón \\
\hline a chin chin & a covanetas & a las acuestas & a rejitu & al recostín & en cuescas & tres de llombu \\
\hline a chon & a cucho & $\begin{array}{l}\text { a las } \\
\text { cachapiernas }\end{array}$ & a rejón & acarreado & en cuestas & $\begin{array}{l}\text { un a } \\
\text { cuesta }\end{array}$ \\
\hline a chon chon & a cuchu & a las costiel.las & $\begin{array}{l}\text { a } \\
\text { repatajones }\end{array}$ & aparratacado & $\begin{array}{l}\text { en las } \\
\text { costillas }\end{array}$ & \\
\hline a cocoletas & $\begin{array}{l}\text { a } \\
\text { cucurumillo }\end{array}$ & a las costiellas & a requicho & arreblagóu & $\begin{array}{l}\text { en } \\
\text { sicuestas }\end{array}$ & \\
\hline a collas & a cuello & a las costilla & a rescolinas & as costas & en troncha & \\
\hline
\end{tabular}

Tabla 1. Locuciones con el significado de 'llevar a cuestas' en el ALPI.

\footnotetext{
${ }^{7}$ Entre estas no se incluyen las de los dominios catalán y gallego-portugués.
} 
Estas formas quedan distribuidas por provincias y localidades de la siguiente manera, según los datos del $A L P I$, en un reparto al que se adjunta el número de casos registrados de cada una de ellas (de un total de 310) y su representación porcentual:

- A cuestas: 66 casos (porcentaje sobre el total [310]: 21,29 \%). León (Laguna Dalga, Calzada del Coto), Zamora (Otero de Bodas, Mahide, Villafáfila, Villarino tras la Sierra, Losacio de Alba, El Pego), Salamanca (Serradilla del Arroyo), Badajoz (Almendral), Cantabria (Vega de Liébana), Palencia (Acera de la Vega, Calzada de Los Molinos, Santa Cecilia del Alcor), Burgos (Castrobarto, Vallarta de Bureba, Pampliega, Pinilla de los Moros, Villanueva de Gumiel), Valladolid (Villavencio de los Caballeros, Langayo), Segovia (Lastras de Cuéllar, Barbolla), Soria (Alcubilla del Marqués, Vinuesa, Yanguas, Muro de Ágreda, Tardajos de Duero, Cihuela, Caltojar, Layna), Ávila (Hernansancho, La Horcajada), Madrid (Rascafría), Guadalajara (Renera, Galve de Sorbe, Vallhermoso), Toledo (Los Yébenes, El Romeral), Cuenca (Albalate de las Nogueras, Honrubia, Cardenete), Ciudad Real (Alcolea de Calatrava, Villarrubia de los Ojos, Pedro Muñoz, Fuencaliente, Carrizosa), Córdoba (Fuenteovejuna, Hornachuelos), Jaén (Baeza, Torre del Campo, Pegalajar, Quesada), Málaga (Cuevas del Becerro, Peñarrubia), Granada (Darro, Zújar, Güéjar-Sierra, Melegís, Mecina-Bombarón), Almería (Fiñana, La Alquería de Adra), Murcia (Ricote, Abanilla).

- En cuestas: 30 casos (porcentaje sobre el total: 9,68\%). Sevilla (Lebrija, Constantina, Fuentes de Andalucía, Gilena), Cádiz (El Bosque, Tarifa), Málaga (Cuevas de San Marcos, Perauta, Manilva, Alhaurín el Grande, Frigiliana), Granada (Zafarraya, Montefrío), Cáceres (Aliseda), Badajoz (Talavera la Real, Campanario, Hornachos, Calera de León), Ciudad Real (Puebla de Don Rodrigo, Fuencaliente, El Viso del Marqués), Córdoba (Pedroche, Villaviciosa, Adamuz, La Carlota, Doña Mencía), Jaén (Marmolejo, La Puerta de Segura, Menjíbar, Castillo de Locubín).

- A las costillas: 11 casos (porcentaje sobre el total: 3,55 \%). Salamanca (Gejuelo del Barro, Retortillo, Valdefuentes de Sangusín), Cáceres (Jarandilla), Soria (Layna), Madrid (Cadalso de los Vidrios, Valdelaguna), Toledo (Cebolla, Camarenilla, Navahermosa), Ciudad Real (Alcolea de Calatrava).

- A la espalda: 9 casos (porcentaje sobre el total: 2,90 \%). Salamanca (Linares de Riofrío), Valladolid (Pedrajas de San Esteban), Madrid (Valdepiélagos), Albacete (Tarazona de La Mancha, Casas de Ves), Badajoz (Ahillones), Cádiz (Chiclana de la Frontera), Almería (Lucainena de las Torres), Murcia (La Paca). 
- A coscoletas: 6 casos (porcentaje sobre el total: 1,94\%). Murcia (Abanilla), Granada (Orce), Almería (Taberno, Alicún de Almería, Cabo de Gata, Mojácar).

- A la costilla: 5 casos (porcentaje sobre el total: 1,61 \%). Salamanca (Campo de Peñaranda, Hinojosa del Duero), Burgos (Pinilla de los Moros), Segovia (Borbolla), Toledo (Sevilleja de la Jara).

- A cotenas: 4 casos (porcentaje sobre el total: 1,29 \%). Zaragoza (Campillo de Aragón, Codos, Letux), Teruel (Segura de los Baños).

- En trunchas: 4 casos (porcentaje sobre el total: 1,29 \%). Huelva (Paymogo, Alosno), Sevilla (Castillo de las Guardas), Badajoz (Valle de Santa Ana).

- A costiellas: 3 casos (porcentaje sobre el total: 0,97 \%). León (Lucillo), Zamora (San Ciprián de Sanabria, San Martín de Castañeda).

- A costillas: 3 casos (porcentaje sobre el total: 0,97 \%). Zamora (Cubo de Benavente), Valladolid (San Cebrián de Mazote), Segovia (Lastras de Cuéllar).

- A las cuestas: 3 casos (porcentaje sobre el total: 0,97\%). Salamanca (Aldea del Obispo, Fuenteguinaldo, El Payo).

- A ricotes: 3 casos (porcentaje sobre el total: 0,97 \%). Álava (Sarría, Ozaeta, San Vicente de Arana).

- Al chin chin: 3 casos (porcentaje sobre el total: 0,97 \%). Teruel (Alfambra, Villarluengo, La Puebla de Valverde).

- As costas: 3 casos (porcentaje sobre el total: 0,97 \%). León (Castroquilame), Cáceres (Valverde del Fresno, Ferreira de Alcántara).

- Levar as costas: 3 casos (porcentaje sobre el total: 0,97 \%). Zamora (Padornelo, Hermisende), Asturias (Cuantas).

- A coscaletas: 2 casos (porcentaje sobre el total: 0,65 \%). Albacete (Agramón), Murcia (La Pinilla de Aravaca).

- A cosqueretas: 2 casos (porcentaje sobre el total: 0,65 \%). Albacete (Higueruela, Caudete de la Encina).

- A cuchu: 2 casos (porcentaje sobre el total: 0,65\%). Cantabria (Bustantegua, Veguilla).

- A cuscaletas: 2 casos (porcentaje sobre el total: 0,65 \%). Murcia (Tiñosa, Cabo de Palos).

- A las acuestas: 2 casos (porcentaje sobre el total: 0,65\%). Palencia (Villaconancio), Guadalajara (Gárgoles de Abajo).

- A las espaldas: 2 casos (porcentaje sobre el total: 0,65\%). Albacete (Letur), Murcia (El Hornico de Ascona).

- A recuestas: 2 casos (porcentaje sobre el total: 0,65 \%). Ávila (Santa Cruz del Valle), Burgos (Manzanedo). 
- A rejón: 2 casos (porcentaje sobre el total: 0,65 \%). Cantabria (Vega de Pas), La Rioja (San Millán de la Cogolla).

- Al cuello: 2 casos (porcentaje sobre el total: 0,65 \%). Castellón (Castillo de Villamalefa y Fanzara).

- Al hombru: 2 casos (porcentaje sobre el total: 0,65\%). Asturias (Busmente, Navelgas).

- Al recostín: 2 casos (porcentaje sobre el total: 0,65\%). Asturias (Nozaleda, Pintueles).

- En coscoletas: 2 casos (porcentaje sobre el total: 0,65 \%). Jaén (Las Navas de Tolosa), Almería (Suflí).

- Aceite: 1 caso (porcentaje sobre el total: 0,323\%). Asturias (Felechosa).

- A aceite: 1 caso (porcentaje sobre el total: 0,323\%). León (Folledo).

- A ambé: 1 caso (porcentaje sobre el total: 0,323 \%). Zaragoza (Chiprana).

- A borriquitos: 1 caso (porcentaje sobre el total: 0,323 \%). Cantabria (Valle de Cabuérniga).

- A burras: 1 caso (porcentaje sobre el total: 0,323 \%). León (Cofiñal).

- A burro: 1 caso (porcentaje sobre el total: 0,323\%). Valencia (Caudete de las Fuentes).

- A caballico: 1 caso (porcentaje sobre el total: 0,323 \%). Navarra (Izalzu).

- A caballo: 1 caso (porcentaje sobre el total: 0,323\%). Huesca (Ansó).

- A caballu: 1 caso (porcentaje sobre el total: 0,323\%). Asturias (Llantones).

- A cabrito: 1 caso (porcentaje sobre el total: 0,323\%). Sevilla (Bormujos).

- A cachón: 1 caso (porcentaje sobre el total: 0,323 \%). León (Torrebarrio).

- A carrapachón: 1 caso (porcentaje sobre el total: 0,323\%). Cáceres (Pinofranqueado).

- A carrapotu: 1 caso (porcentaje sobre el total: 0,323 \%). Asturias (Villanueva de Teberga).

- A carricotes: 1 caso (porcentaje sobre el total: 0,323 \%). Burgos (Treviño).

- A carrinchoncha: 1 caso (porcentaje sobre el total: 0,323 \%). Huelva (Villablanca).

- A carriquicho: 1 caso (porcentaje sobre el total: 0,323 \%). Beci (Vizcaya).

- A chinchín: 1 caso (porcentaje sobre el total: 0,323 \%). Cuenca (Valdemoro de la Sierra).

- A chin chin: 1 caso (porcentaje sobre el total: 0,323\%). Teruel (Bronchales).

- A chon: 1 caso (porcentaje sobre el total: 0,323 \%). Ávila (Las Navas del Marqués).

- A chon chon: 1 caso (porcentaje sobre el total: 0,323 \%). Navarra (Orísoain).

- A cocoletas: 1 caso (porcentaje sobre el total: 0,323 \%). Murcia (La Paca).

- A collas: 1 caso (porcentaje sobre el total: 0,323 \%). Huesca (La Pobla de Roda).

- A colletes: 1 caso (porcentaje sobre el total: 0,323 \%). Huesca (Benasque).

- A conches: 1 caso (porcentaje sobre el total: 0,323 \%). Burgos (Castrobarto).

- A concos: 1 caso (porcentaje sobre el total: 0,323 \%). La Rioja (Pradejón).

- A cones: 1 caso (porcentaje sobre el total: 0,323 \%). Cantabria (Veguilla). 
- A costaletas: 1 caso (porcentaje sobre el total: 0,323\%). Murcia (Fuente del Pino).

- A costas: 1 caso (porcentaje sobre el total: 0,323 \%). Asturias (Boal).

- A costetas: 1 caso (porcentaje sobre el total: 0,323 \%). Huesca (Loarre).

- Llevar a costilla: 1 caso (porcentaje sobre el total: 0,323 \%). Guadalajara (La Toba).

- A costillinas: 1 caso (porcentaje sobre el total: 0,323 \%). Zamora (Fariza).

- A costinas: 1 caso (porcentaje sobre el total: 0,323 \%). León (Pontedo).

- A costrinas: 1 caso (porcentaje sobre el total: 0,323 \%). Salamanca (Villarino de los Aires).

- A cotetas: 1 caso (porcentaje sobre el total: 0,323 \%). Navarra (Uscarés).

- A covanetas: 1 caso (porcentaje sobre el total: 0,323 \%). Cantabria (Miera).

- A cucho: 1 caso (porcentaje sobre el total: 0,323\%). Cantabria (Yermo).

- A cucurumillo: 1 caso (porcentaje sobre el total: 0,323 \%). Murcia (Tiñosa).

- A cuello: 1 caso (porcentaje sobre el total: 0,323\%). Valencia (Dos Aguas).

- A cuestes: 1 caso (porcentaje sobre el total: 0,323 \%). Asturias (Llantones).

- A cullacas: 1 caso (porcentaje sobre el total: 0,323\%). Huesca (Fonz).

- A curumbillo: 1 caso (porcentaje sobre el total: 0,323 \%). Granada (La Garnatilla).

- A as costillas: 1 caso (porcentaje sobre el total: 0,323 \%). Huesca (Alquézar).

- A en colicas: 1 caso (porcentaje sobre el total: 0,323 \%). Huesca (Peralta de Alcofea).

- A en coquetas: 1 caso (porcentaje sobre el total: 0,323 \%). Zaragoza (Sos del Rey).

- A en culecas: 1 caso (porcentaje sobre el total: 0,323 \%). Huesca (Alquézar).

- A escarramanchón: 1 caso (porcentaje sobre el total: 0,323 \%). Zaragoza (Monegrillo).

- $A$ jitas: 1 caso (porcentaje sobre el total: 0,323 \%). Palencia (Cardaño de Abajo).

- A la carga leña: 1 caso (porcentaje sobre el total: 0,323 \%). Toledo (Lagartera).

- A la chin: 1 caso (porcentaje sobre el total: 0,323\%). Teruel (Blancas).

- A la esquena: 1 caso (porcentaje sobre el total: 0,323 \%). Huesca (Benasque).

- A la pela: 1 caso (porcentaje sobre el total: 0,323 \%). Badajoz (Alburquerque).

- A la recacha: 1 caso (porcentaje sobre el total: 0,323 \%). Asturias (Pola de Somiedo).

- A las cachapiernas: 1 caso (porcentaje sobre el total: 0,323\%). Asturias (La Mata).

- A las costiel.las: 1 caso (porcentaje sobre el total: 0,323 \%). León (Páramo del Sil).

- A las costiellas: 1 caso (porcentaje sobre el total: 0,323 \%). León (Lillo de Bierzo).

- A las costilla: 1 caso (porcentaje sobre el total: 0,323 \%). Huesca (Bielsa).

- A loilos: 1 caso (porcentaje sobre el total: 0,323 \%). Palencia (Acera de la Vega).

- A marchante: 1 caso (porcentaje sobre el total: 0,323 \%). Navarra (Goñi).

- A memé: 1 caso (porcentaje sobre el total: 0,323 \%). Granada (Güéjar-Sierra).

- A patarrajones: 1 caso (porcentaje sobre el total: 0,323 \%). Córdoba (Belalcázar).

- A perejetes: 1 caso (porcentaje sobre el total: 0,323 \%). Burgos (Sotresgudo). 
- A quetas: 1 caso (porcentaje sobre el total: 0,323 \%). Cantabria (Balbacienta).

- A rajetos: 1 caso (porcentaje sobre el total: 0,323 \%). Cantabria (La Costana).

- A recachu: 1 caso (porcentaje sobre el total: 0,323\%). Asturias (Santiago del Monte).

- A recocho: 1 caso (porcentaje sobre el total: 0,323 \%). Álava (Zuaza).

- A la rica: 1 caso (porcentaje sobre el total: 0,323 \%). Asturias (Soto de la Barca).

- A recotas: 1 caso (porcentaje sobre el total: 0,323 \%). Burgos (Villalba de la Losa).

- A rejetas: 1 caso (porcentaje sobre el total: 0,323 \%). Cantabria (Resconorio).

- A rejín: 1 caso (porcentaje sobre el total: 0,323 \%). Cantabria (Espinama).

- A rejito: 1 caso (porcentaje sobre el total: 0,323 \%). Palencia (Brañosera).

- A rejitu: 1 caso (porcentaje sobre el total: 0,323 \%). Cantabria (Espinama).

- A repatajones: 1 caso (porcentaje sobre el total: 0,323 \%). Ávila (Grajos).

- A requicho: 1 caso (porcentaje sobre el total: 0,323 \%). Álava (Zuaza).

- A rescolinas: 1 caso (porcentaje sobre el total: 0,323 \%). Asturias (Malveda).

- A rexolinas: 1 caso (porcentaje sobre el total: 0,323 \%). León (Folledo).

- A sarrajitos: 1 caso (porcentaje sobre el total: 0,323 \%). Cantabria (Tudanca).

- A xocastrinas: 1 caso (porcentaje sobre el total: 0,323\%). Asturias (Felechosa).

- Al arre: 1 caso (porcentaje sobre el total: 0,323\%). Asturias (Nozaleda).

- Al chin: 1 caso (porcentaje sobre el total: 0,323\%). Castellón (Azuébar).

- Al chinchín: 1 caso (porcentaje sobre el total: 0,323\%). Teruel (Mosqueruela).

- Al chinchu: 1 caso (porcentaje sobre el total: 0,323 \%). Asturias (Los Carriles).

- Al chulchi: 1 caso (porcentaje sobre el total: 0,323 \%). Cáceres (Madroñera).

- Al churchi: 1 caso (porcentaje sobre el total: 0,323 \%). Cáceres (Madroñera).

- Al cordero: 1 caso (porcentaje sobre el total: 0,323 \%). Valencia (Pedralba).

- Al cuadril: 1 caso (porcentaje sobre el total: 0,323 \%). Cáceres (Aliseda).

- Al cuairí: 1 caso (porcentaje sobre el total: 0,323 \%). Cáceres (Ceclavín).

- Al jarrique: 1 caso (porcentaje sobre el total: 0,323 \%). León (Pío).

- Al oilo: 1 caso (porcentaje sobre el total: 0,323 \%). Burgos (Hontomín).

- Acarreado: 1 caso (porcentaje sobre el total: 0,323\%). Málaga (Olías).

- Aparratacado: 1 caso (porcentaje sobre el total: 0,323 \%). Málaga (Cuevas del Becerro).

- Arreblagóu: 1 caso (porcentaje sobre el total: 0,323 \%). Asturias (Cimalavilla).

- Cuestas: 1 caso (porcentaje sobre el total: 0,323 \%). Cuenca (Carrascosa del Campo).

- Culleca: 1 caso (porcentaje sobre el total: 0,323\%). Sant Esteve de Llitera (Huesca).

- Echar en cuestas: 1 caso (porcentaje sobre el total: 0,323 \%). Albacete (Peñas de San Pedro).

- Embá: 1 caso (porcentaje sobre el total: 0,323 \%). Zaragoza (Tierga). 
- En cabrito: 1 caso (porcentaje sobre el total: 0,323 \%). Cádiz (Alcalá de los Gazules).

- En carilota: 1 caso (porcentaje sobre el total: 0,323\%). Huelva (Almonte).

- En clavito: 1 caso (porcentaje sobre el total: 0,323\%). Sevilla (Cantillana).

- En coquetas: 1 caso (porcentaje sobre el total: 0,323 \%). Zaragoza (Farasdués).

- En corderetas: 1 caso (porcentaje sobre el total: 0,323 \%). Zaragoza (Boquiñeni).

- En corderetes: 1 caso (porcentaje sobre el total: 0,323 \%). Zaragoza (Farasdués).

- En corderos: 1 caso (porcentaje sobre el total: 0,323 \%). Navarra (Arguedas).

- En cotenas: 1 caso (porcentaje sobre el total: 0,323 \%). Zaragoza (Cadrete).

- En cotines: 1 caso (porcentaje sobre el total: 0,323 \%). Teruel (Alloza).

- En as costilla: 1 caso (porcentaje sobre el total: 0,323 \%). Huesca (Ansó).

- En as costillas: 1 caso (porcentaje sobre el total: 0,323 \%). Huesca (Borau).

- En crabito: 1 caso (porcentaje sobre el total: 0,323 \%). Sevilla (Cantillana).

- En cucú: 1 caso (porcentaje sobre el total: 0,323\%). Sevilla (El Coronil).

- En cuescas: 1 caso (porcentaje sobre el total: 0,323 \%). Sevilla (Saucejo).

- En las costillas: 1 caso (porcentaje sobre el total: 0,323 \%). Huesca (Torla).

- En sicuestas: 1 caso (porcentaje sobre el total: 0,323 \%). Badajoz (Fuente del Maestre).

- En troncha: 1 caso (porcentaje sobre el total: 0,323 \%). Huelva (Cortegana).

- En trucha: 1 caso (porcentaje sobre el total: 0,323 \%). Badajoz (Valencia de Mombuey).

- En truncha: 1 caso (porcentaje sobre el total: 0,323 \%). Huelva (Cortegana).

- En trunche: 1 caso (porcentaje sobre el total: 0,323 \%). Huelva (Valverde del Camino).

- Escarramau: 1 caso (porcentaje sobre el total: 0,323 \%). Valencia (Pedralba).

- Escarrapachado: 1 caso (porcentaje sobre el total: 0,323 \%). Salamanca (Hinojosa del Duero).

- H.arriquín: 1 caso (porcentaje sobre el total: 0,323\%). Asturias (Cimiano).

- L.levar a recostines: 1 caso (porcentaje sobre el total: 0,323 \%). Asturias (Cenera).

- L.levar a recachas: 1 caso (porcentaje sobre el total: 0,323\%). Asturias (Santa Eulalia).

- Levar as costa: 1 caso (porcentaje sobre el total: 0,323\%). Asturias (Salgueiras).

- Levar ás garabitolas: 1 caso (porcentaje sobre el total: 0,323\%). Asturias (As Campas).

- Levar o carrelo: 1 caso (porcentaje sobre el total: 0,323\%). León (Castroquilame).

- Llevallo as costas: 1 caso (porcentaje sobre el total: 0,323\%). Asturias (Freal).

- Llevarlu aceite: 1 caso (porcentaje sobre el total: 0,323 \%). León (Omañón).

- Montado: 1 caso (porcentaje sobre el total: 0,323 \%). Cáceres (Ceclavín).

- O riquichu: 1 caso (porcentaje sobre el total: 0,323 \%). León (Ponte de Rey).

- Rejón: 1 caso (porcentaje sobre el total: 0,323 \%). Burgos (Hontomín).

- Tres de llombu: 1 caso (porcentaje sobre el total: 0,323\%). Asturias (Sames).

- Un a cuesta: 1 caso (porcentaje sobre el total: 0,323 \%). Madrid (Cadalso de los Vidrios). 
Como puede observarse, a cuestas es la variante más frecuente $(21,29 \%$, bastante por encima de las demás), y es la que muestra una mayor extensión geográfica, pues está registrada en 22 provincias pertenecientes a siete comunidades autónomas: Castilla y León, Extremadura, Cantabria, Madrid, Castilla-La Mancha, Andalucía y Murcia. A cierta distancia, pero también con cierta frecuencia de uso $(9,68$ $\%)$, se encuentra otra variante (en cuestas) que tan solo presenta un cambio respecto de la anterior (la preposición utilizada), y que está documentada en diez provincias, todas ellas de Andalucía y Extremadura, excepto Ciudad Real.

A continuación se sitúa a las costillas (esta última palabra, también derivada del latín costa) con un porcentaje de uso de un 3,55 \% y que está registrada en seis provincias, pertenecientes a las comunidades autónomas de Castilla y León, Castilla-La Mancha, Extremadura y Madrid. Cerca (2,90 \%) se sitúa otra locución cuyo sustantivo incide también en la parte del cuerpo sobre la que se lleva la carga (a la espalda), y que recubre áreas de Castilla y León, Madrid, Castilla-La Mancha, Extremadura, Andalucía y Murcia. A coscoletas, por su parte, presenta un porcentaje de uso del 1,94 \%, y se registra en tres provincias: Murcia, Granada y Almería. Muy cerca de la anterior en cuanto a frecuencia de utilización $(1,61 \%)$ se sitúa a la costilla, cuyo empleo se ubica en cuatro provincias, tres de Castilla y León y una de Castilla-La Mancha. A cotenas tiene un porcentaje de uso del 1,29 \% y se extiende por dos provincias de Aragón: Zaragoza y Teruel. En cuanto a en trunchas, presenta igual frecuencia que la anterior $(1,29 \%)$, si bien geográficamente queda emplazada en dos provincias de Andalucía y una de Extremadura.

Seguidamente cabría situar siete locuciones que presentan un mismo número de registros (3) y, obviamente, igual porcentaje de uso: 0,97 \%. Se trata de a costiellas, a costillas, a las cuestas, a ricotes, al chin chin, as costas y levar as costas. Si atendemos a la distribución espacial de las anteriores formas, debemos señalar que el uso de $a$ costiellas se produce en dos provincias de Castilla y León (León y Zamora); el de $a$ costillas, en tres provincias de Castilla y León (Zamora, Valladolid y Segovia); el de a las cuestas, en una provincia de Castilla y León (Salamanca); el de as costas, en una provincia de Castilla y León (León) y en una provincia de Extremadura (Cáceres); el de 
levar as costas, en una provincia de Castilla y León (Zamora) y en Asturias. Las variantes a ricote y al chin chin se encuentran registradas, respectivamente, en una provincia del País Vasco (Álava) y en una de Aragón (Teruel).

En cuanto a las doce formas que presentan dos registros, cabe mencionar que algunas como a coscaletas, a cuscaletas, en coscoletas y a cosqueretas presentan muy pocas variaciones, $y$, en este caso concreto, quedan ubicadas entre Albacete y/o Murcia, excepto en coscoletas, circunscrita a Jaén y Almería.

Por último, hay 130 variantes que presentan un único registro, si bien este dato requiere matización, pues en muchos casos comparten origen y/o presentan pocas variaciones entre sí. De hecho, esto no solo sucede con este último grupo, sino que si tenemos en cuenta todas las variantes con el significado 'llevar a cuestas' registradas en el $A L P I$, podemos comprobar que hay entre ellas algunas afinidades evidentes. En efecto, gran parte deriva del latín costa 'costilla, costado': a costaletas, a costas, a costetas, a costinas, a costrinas, a cuestas, a cuestes, a las acuestas, a las cuestas, a recotas, a recuestas, as costas, cuestas, echar en cuestas, en cuestas, en sicuestas, I.levar a recostines, levar as costa, levar as costas, llevallo as costas, un a cuesta, a costiellas, a costilla a costillas, a costillinas, a cotetas, a as costillas, a la costilla, a las costiel.las, a las costiellas, a las costilla, a las costillas, en as costilla, en as costillas, en las costillas.

Se trata de un inventario en el que se encuentran, además, algunas de las variantes del ALPI más frecuentes en cuanto a uso. Por ello, y si las consideramos en conjunto, podemos afirmar que, según el citado atlas lingüístico, 35 de un total de 157 formas $(22,29 \%)$ utilizadas en la codificación de la noción 'llevar a cuestas' parte en su construcción del étimo latino costa. Y en lo que se refiere a su frecuencia de uso, de estas variantes habría 155 casos de 310 (50\%).

Las anteriores no son las únicas UF en las que figura una parte del cuerpo, sino que hay otras en las que sucede lo mismo. Así, del latín cŏLlum proceden a cuello, al cuello, a colletes, a collas, a cullacas, a en colicas, a en culecas y culleca. ${ }^{8}$ Del latín coxA 'cadera' derivan a cucho y a cuchu; del latín tardío SPATŬLA 'omóplato', 'espátula', dim.

\footnotetext{
${ }^{8}$ Terrón Vinagre (2015: 17) señala, entre las denominaciones de llevar a cuestas relacionadas con la palabra cuello, colleca(s), en collecas, colletas, en colletas, ancolletas, colleres, ancollas.
} 
de spatha 'pala', a la espalda y a las espaldas; al cuadril (y probablemente también al cuairí), por *cadril, de cadera; del latín HUMĔRUs, al hombru; y del gót. *skĭna 'barrita', 'tibia'; cf. alto alemán antiguo scina 'tibia', 'alfiler', a la esquena. Por su parte, pela aparece definido como "espalda" en el Diccionario histórico del español de Canarias (DHECan) a partir de una única documentación: el Pequeño vocabulario de Armas Ayala (1944); aunque se añade que "parece tratarse de una significación «deducida» de la locución a la pela, que es realmente donde la palabra tiene un uso normal y general" (https://webfrl.rae.es/dhecan.html). A continuación se indica que a la pela tiene su origen en el portugués péla, niña que bailaba sobre los hombros de una mujer. Esta UF, "de amplio empleo en las islas [Canarias] (vid. el ALEICan II, 706 "(Llevar) a hombros» y 707 "(Llevar) a cuestas»)" (ibid.), está documentada en el ALPI en Alburquerque (Badajoz).

Y de carrelo (ALPI: levar o carrelo) se señala en la versión digital del Léxico del leonés actual (LLA) de Jeannick Le Men Loyer (s. v. carrillo) que en la parte berciana de habla gallega "se emplea la palabra [carrillo] (bajo la forma carrelo) con el significado de 'espalda', como en gallego y portugués" (https://lla.unileon.es/?id=EC103295), y se señala acerca del origen de carrillo [carriello | carriechxu | carrelo] (ibid.):

De origen incierto: "Como antiguamente significó 'quijada', puede ser diminutivo de carro, por el movimiento de vaivén de las quijadas al masticar" [apud [502]]. "En favor de su idea, puede citarse el berciano carrelo 'la parte superior de la espalda, entre los hombros', que pudo llamarse así por el movimiento de vaivén de los omoplatos". Se registran también distintas propuestas, entre otras la de Krüger y no se descarta la de Covarrubias, quien deriva carrillo de cara.

También en el LLA se explica que carracachaperna (llevar a) (ALPI: a las cachapiernas) [cachaperna | carrachaperna | carrapacheta] es una forma expresiva hecha sobre carraca, cacha y perna (https://lla.unileon.es/?id=EC103233). Finalmente, en tres de llombu la última palabra (< latín lŭmbus) alude también a una parte del cuerpo: “Cepeda: Ilombu, 'lomo, espalda, espinazo', 'caballón de surco'” (LLA. Entrada: lombo, https://lla.unileon.es/?id=EC110051). 
Por otro lado, también hay UF relacionadas con nombres de animales. En efecto, del latín tardío burrīcus 'caballo pequeño' procede borrico, ca (a borriquitos), y de este, burro, rra (a burras, a burro); del latín caballus 'caballo de carga', caballo (a caballico, a caballo, a caballu); del diminutivo de cabro (< latín caper, -pri), cabrito, ta (a cabrito, en cabrito, en crabito, y seguramente en clavito); y del latín vulg. *cordarius, derivado de cordus 'tardío', cordero, ra (al cordero, en corderetas, en corderetes, en corderos).

Asimismo hay variantes de las que no siempre es fácil rastrear su origen, aunque estén emparentadas claramente entre sí. Se trata de casos como a chinchín, a chin chin, a la chin, al chin, al chin chin, al chinchín; a chon, a chon chon; al chulchi, al churchi; o en troncha, en trucha, en truncha, en trunchas, en trunche.

Terrón Vinagre (2015) hace referencia justamente a esa dificultad cuando acude a Bernat \& Torres (2004: 208), por ejemplo, para intentar aclarar el significado de chinchín:

És molt possible que aquests mots provinguin de l'àrab SINSIN, un substantiu masculí que significa "gepa; zona de dalt de les vertebres" o de la variant femenina SINSINA(T), "apòfisi de les vertebres dorsals". A més, cal tenir present que la fricativa alveolar sorda del àrab té un fort matís palatal que explicaria les palatalitzacions que trobem a la majoria de les formes. Estas variantes se hallan en zonas próximas a localidades de habla catalana, Teruel (103, $302,303,305,400,402,504)$, Castellón $(300,302)$, Zaragoza (507) y Cuenca (205), y se extienden hacia Navarra $(201-204,402)$ (Terrón Vinagre, 2015: 27).

Y alude también al origen de otras locuciones:

De entre los derivados de costal destaca la designación coscoletas (30) debido al número de ocurrencias. Se ha considerado coscoletas como derivado de costal, puesto que se cree que ha sufrido los siguientes cambios fónicos: costal > costaletas (inclusión del sufijo -eta(s)) > coscaletas (disimilación progresiva de oclusivas sordas $\mathrm{t}>\mathrm{k}$ ) > coscoletas (asimilación de vocales $\mathrm{a}>0$ ) (Terrón Vinagre, 2015: 22).

La designación a/en cotenas, a pesar de aparecer como lema en el Diccionario de voces aragonesas (Borao 1859) y en el de Gaspar y Roig (1853), no se (sic) explica el origen de esta voz y en su definición remite a en corderetas y a horcajadas. Lo mismo ocurre con la denominación colicas (en collicas, ancolicas, en colias), también incluida como lema en Endize de bocables de l'aragonés, II 
(1999): Colicas (en). 'ir un niño sobre la espalda de otro' (Terrón Vinagre, 2015: 27-28).

Por su parte, García de Diego (1964: 579) intenta aclarar el origen de a concos y señala que "es posible que se aluda al conco navarro 'cuenco', comparando al niño con el cántaro que llevan a la cabeza las mujeres"; y el de esquena: "EsquenA (A). En Cataluña por 'a cuestas'. Esquena desde la idea del germ. skina 'espinilla' ha llegado en el catalán al sentido del 'espinazo' y de este al de 'espalda'” (ibid.: 574).

Y sobre las expresiones al oilo o aloilo (ALPI: al oilo, a loilos), se señala en el LLA que el sustantivo procede del latín ŏlěum 'aceite' y que "Los niños decían también hasta hace poco: Cógeme al oilo, significando 'llévame a cuestas'. La expresión al oilo se tomó del pregón de los arrieros que entraban en los pueblos gritando: iAl oilo, jabón, aceite, vinagre, azúcar y arroz!; llevan la carga a lomos de un macho, en unos cajones de madera; hoy hay menos y suelen llevar carro, pero en los pueblos del valle, que no tienen carretera, siguen yendo con el macho" (https://lla.unileon.es/?id=EC111412). Y se insiste más adelante en esta idea: "En algunos sitios al oilo significa 'a cuestas': (coger al oilo), ya que los arrieros llevaban el aceite a lomos de caballerías" (ibid.). Muy probablemente esta explicación es válida también para aceite, a aceite, Ilevarlu aceite, aunque en la citada obra (en la entrada correspondiente a a aceites [llevar]) no se hace referencia a este hecho.

Por último, de todas las locuciones localizadas, el Diccionario de la lengua española $(D L E)$ de la RAE recoge solo unas pocas, prueba de que muchas de ellas son muestras de la lengua rural y/o de que tienen un carácter demasiado local: a cuestas (entrada: cuesta $^{1}$ ) (del lat. costa 'costilla', 'costado'. 1. loc. adv. Sobre los hombros o las espaldas. 2. loc. adv. A su cargo, sobre sí); llevar a alguien a cuestas (entrada: cuesta $^{1}$ ) (1. loc. verb. coloq. Cargarse con sus obligaciones o necesidades); esquena (del gót. *skĭna 'barrita', 'tibia'; cf. a. al. ant. scina 'tibia', 'alfiler', con el significado de columna vertebral); a cucho (entrada: $c u c h o^{3}$ ) (del lat. coxa 'cadera', loc. adv. Cantb. con el valor de 'a hombros'); y a escarramanchones (entrada: escarramanchones) (del arag. escarramar 'ponerse a horcajadas', y este quizá cruce de escarrerar 'descarriar' y derramar. loc. adv. Ar. a horcajadas). 
En el siguiente apartado rastrearemos el uso de estas locuciones y podremos comprobar cómo algunas han continuado su andadura en español hasta llegar a la actualidad y se utilizan tanto en España como en América, mientras de otras no hemos encontrado documentación o restringen su uso a áreas dialectales muy concretas o a la oralidad.

\section{Registro de las UF analizadas en el COSER, CORPES XXI, Corpus del Español y Google}

El rastreo de las unidades fraseológicas mencionadas en el COSER, CORPES XXI, Corpus del Español y Google arroja datos significativos respecto del tema que nos ocupa. Hemos partido de la consulta de estas fuentes por las siguientes razones:

1. El COSER es un corpus oral centrado en el español rural, por lo que es posible encontrar en él datos no reflejados en corpus de carácter más general, conocidos habitualmente como de referencia. Además, los datos recabados provienen de entrevistas semidirigidas realizadas a hablantes de distintas zonas rurales de avanzada edad (la media es de 73 años), depositarios de tradiciones y de usos lingüísticos que pueden estar perdiéndose o aminorándose en generaciones más jóvenes o en áreas urbanas.

2. Pese a lo señalado en el punto anterior, el uso de corpus de referencia presenta como ventaja el acceso a una radiografía del idioma de carácter global. Por eso también se ha acudido al CORPES XXI, corpus de referencia confeccionado por la Real Academia Española que incluye 25 millones de formas y contiene "textos de todos los tipos y también de todos los países que constituyen el mundo hispánico" (https://tinyurl.com/y39jt53c).

3. El Corpus del Español (CE), creado por Mark Davies, es también para nosotros una referencia importante, porque "contiene unos 2000 millones de palabras del español, tomadas de unos dos millones de páginas web de 21 países hispanohablantes diferentes" (https://www.corpusdelespanol.org/web-dial/). Además, en el año 2016 se introdujeron en él nuevas incorporaciones que permiten acceder a información 
relativa a la variación dialectal (sección Web / Dialectos), aspecto clave para nuestros intereses.

4. Google es un buscador con una amplísima base de datos que ayuda a encontrar ocurrencias en aquellos casos no contemplados en los corpus, e incluso a acceder a ciertos textos no siempre fáciles de hallar por distintas razones, pero que afortunadamente han sido digitalizados y colgados en la red. Además, recoge, en no pocas ocasiones, el empleo de unidades léxicas de carácter local, dudas y discusiones de los hablantes acerca de su uso, hipótesis sobre su origen, etc.

Es necesario señalar que las respuestas del $A L P I$, como atlas lingüístico, corresponden a una encuesta sistemática a partir de una pregunta concreta de su cuestionario, mientras que en los corpus no se produce tal circunstancia. En un futuro estas búsquedas serán completadas con la consulta de los atlas lingüísticos posteriores: Atlas lingüístico y etnográfico de Andalucía (ALEA), Atlas lingüístico y etnográfico de las Islas Canarias (ALEICan), Atlas lingüístico y etnográfico de Cantabria (ALECant), Atlas Lingüístico de Castilla y León (ALCyL), Atlas lingüístico (y etnográfico) de Castilla-La Mancha (ALeCMan) y Atlas dialectal de Madrid (ADiM). En este artículo, no obstante, nos interesa conocer el reflejo que las locuciones en cuestión alcanzan en tres importantes corpus y en la Red.

La recolección y análisis de los datos permite constatar que las 22 variantes siguientes no cuentan con documentación en ninguna de las fuentes manejadas. Las recogemos en la siguiente tabla:

\begin{tabular}{|c|c|c|c|}
\hline a ambé / embá & a la carga leña & a ricotes & en cucú \\
\hline a carrinchoncha & a marchante & a xocastrinas & en cuescas \\
\hline a carriquicho & a memé & al chulchi / al churchi & h.arriquín \\
\hline a conches & a quetas & arreblagóu & levar o carrelo \\
\hline a covanetas & a la rica & en carilota & tres de llombu \\
\hline
\end{tabular}

Tabla 2. Locuciones con el significado de 'llevar a cuestas' en el ALPI sin registro de documentación en las fuentes consultadas.

Una posible explicación a esta ausencia documental es que algunas de las anteriores UF estén en franco retroceso porque hay otras más extendidas y, por ello, son más versátiles en cuanto a posibles contextos y ámbitos de utilización. La 
existencia de una sociedad harto globalizada en que la conexión y la relación entre los territorios es cada vez mayor es un factor que ha de ser tenido en cuenta. Además, es de todos conocido que la variación (también la diacrónica) es una característica intrínseca de las lenguas, y los datos procedentes del $A L P I$ fueron tomados en la década de los 30 de la pasada centuria. Las palabras de Pons Rodríguez (2020: 213214) a propósito del andaluz refrendan esta visión:

La historia trae una herencia, pero cada presente la modifica a su manera. En la actualidad, sobre el vocabulario andaluz distintivo y propio se proyecta la sombra de la globalización léxica. Es un fenómeno que se advierte, en general, para muchas de las lenguas actuales: pierden mucho léxico dialectal en favor del estándar, que llega por los medios, la publicidad y la escolarización. El proceso puede ser más o menos inconsciente: aunque en las casas andaluzas se cocinen alcauciles y papas, estas voces se van reemplazando por alcachofas y patatas; lo mismo ocurrirá con la lluvia fina o harinilla, sustituida progresivamente por un chirimiri que el español tomó del vascuence; lo que se compra en las tiendas es colonia de lavanda y pocos relacionarán ese nombre con alhucema.

También puede suceder que se trate de UF de uso bastante restringido a una zona o región y por eso se evita su utilización ante hablantes de otros lugares (puede ser el caso de los testimonios recogidos en el COSER, basados en la realización de entrevistas semidirigidas en las que el entrevistador no es de la zona de origen del entrevistado), o en textos en los que se opta por una variedad estándar o niveladora. En línea con esta afirmación cabe situar las reflexiones de Llorente Pinto (2005: 688689), a propósito de la relación existente entre léxico disponible ${ }^{9}$ y dialectal en la provincia de Ávila:

Es evidente que en el estudio dialectal muchas realidades se expresan con varios términos y esos términos son en buena medida dialectales, locales o tradicionales; frente a esta situación nos encontramos con un vocabulario disponible totalmente estándar, donde la presencia de los dialectalismos es insignificante y meramente residual: son respuestas de muy pocos informantes, como pueden ser los casos de cucharrena 'espumadera', o guango 'cobertizo', soluciones aportadas por una única persona, o sobrado 'desván' y pipo 'alubia',

\footnotetext{
9 "El léxico disponible se define como «aquel que viene rápida y fácilmente a la mente del hablante cuando la conversación gira en torno a un determinado tema»" (Llorente Pinto 2005: 681).
} 
que son los dialectalismos más disponibles al haber sido elegidos por siete informantes.

Parece general el hecho de que en los léxicos disponibles no aparezcan muchos vocablos autóctonos. González Martínez (1999) encuentra solo un 1.34 \% de términos dialectales en el léxico disponible de Cádiz, y Hernández Muñoz (2005), un 1.27 \% en el léxico castellano-manchego; Hernández Cabrera y Samper Padilla (2003) no dan datos totales de voces canarias pero los aportados en ciertos campos hacen presuponer que la nómina de estos sea algo mayor.

Aunque a continuación también se alude a la posibilidad de que el diseño de las encuestas y el tema tratado en ellas pueda favorecer la inclusión o exclusión de léxico dialectal en las alocuciones de los informantes, postura que suscribimos plenamente:

Aun así, Samper, Bellón y Samper Hernández (2003) se preguntan si la escasez de dialectalismos se debe al propio tipo de encuesta para recabar el léxico, que no favorece la aparición de regionalismos, excepto en los centros más apegados al medio y a las tradiciones locales, como son los de 5. Alimentos y bebidas, 11. El Campo y 14. Los animales (Llorente Pinto 2005: 689).

Incluso podría darse el caso de que las UF en cuestión formaran parte de un léxico pasivo que las generaciones más jóvenes entienden, pero que apenas utilizan:

Sin embargo, en una misma zona conviven varias generaciones que se entienden y se comunican y no lo hacen solo a través del léxico disponible sino de un léxico pasivo que conocen y comprenden. El léxico pasivo entonces cobra importancia, y se convierte en un factor digno de ser tenido en cuenta para la comunicación interdialectal e intergeneracional (Llorente Pino 2005: 689).

Asimismo hay no pocos casos de UF que se encuentran únicamente en lo que puede catalogarse como fuentes de carácter secundario (FS), etiqueta bajo la cual incluimos artículos y trabajos de carácter científico y académico, diccionarios u otros repertorios lexicográficos, así como blogs y foros en los que se plantean discusiones acerca del significado, dispersión geográfica y empleo de una determinada UF.

Es importante señalar que la inclusión de este tipo de expresiones en FS parece obedecer, al menos en ciertos casos, a un deseo de conservarlas como seña de identidad del habla de determinados territorios. De ahí que sean objeto de discusión 
en foros de Internet, o que los repertorios lexicográficos confeccionados acerca de ciertas expresiones propias de una zona concreta estén patrocinados en no pocos casos por instituciones oficiales.

En realidad, se trata de testimonios metalingüísticos que denotan usos y contextos de aparición muy restringidos. Entre ellos puede haber variantes del $A L P I$ no documentadas stricto sensu, pero que presentan pocas variaciones respecto de otras formas registradas en las citadas fuentes. También puede suceder que de una determinada forma no hayamos encontrado ocurrencias, pero sí de otra(s) UF que tiene(n) o parece(n) tener el mismo origen. De hecho, la coincidencia geográfica, cuando pudiera haber dudas al respecto, nos ha llevado también en ocasiones a optar por cierto modo de agrupación.

Recogemos todas esas variantes en la siguiente tabla, en la que hemos escrito en cursiva aquellas del $A L P I$ de las que hay documentación; y hemos incluido entre paréntesis las variantes encontradas (cuando no se ha hallado documentación de las formas literales del $A L P I$, pero sí otras muy próximas a ellas) u otras variantes encontradas (cuando, además de la(s) del $A L P I$, hay otras no registradas en él). Tras la tabla en cuestión figuran los correspondientes ejemplos, en los que resaltamos en negrita aquellas expresiones sobre las que nos interesa llamar la atención:

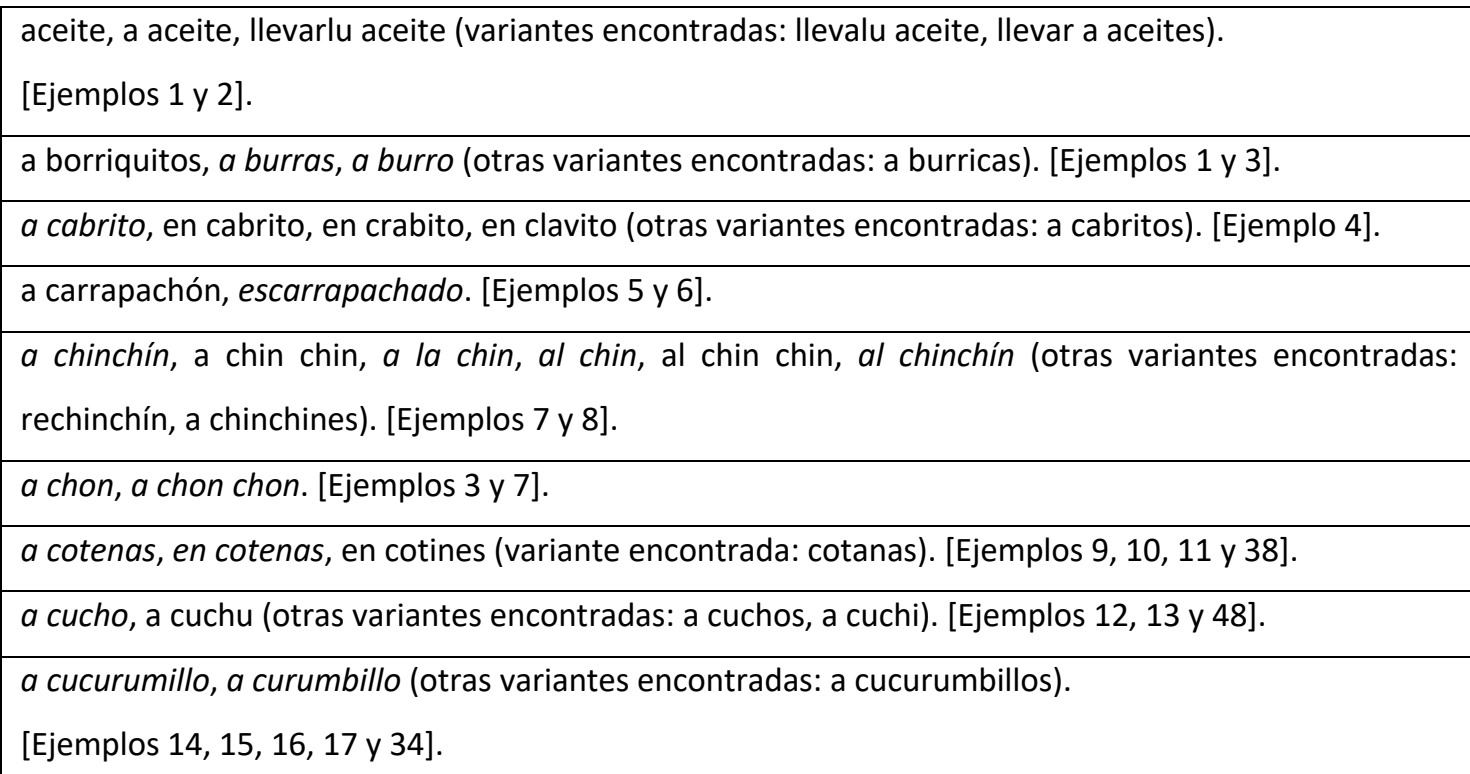


Dialectologia. Special issue, IX (2021), 151-192.

ISSN: 2013-2247

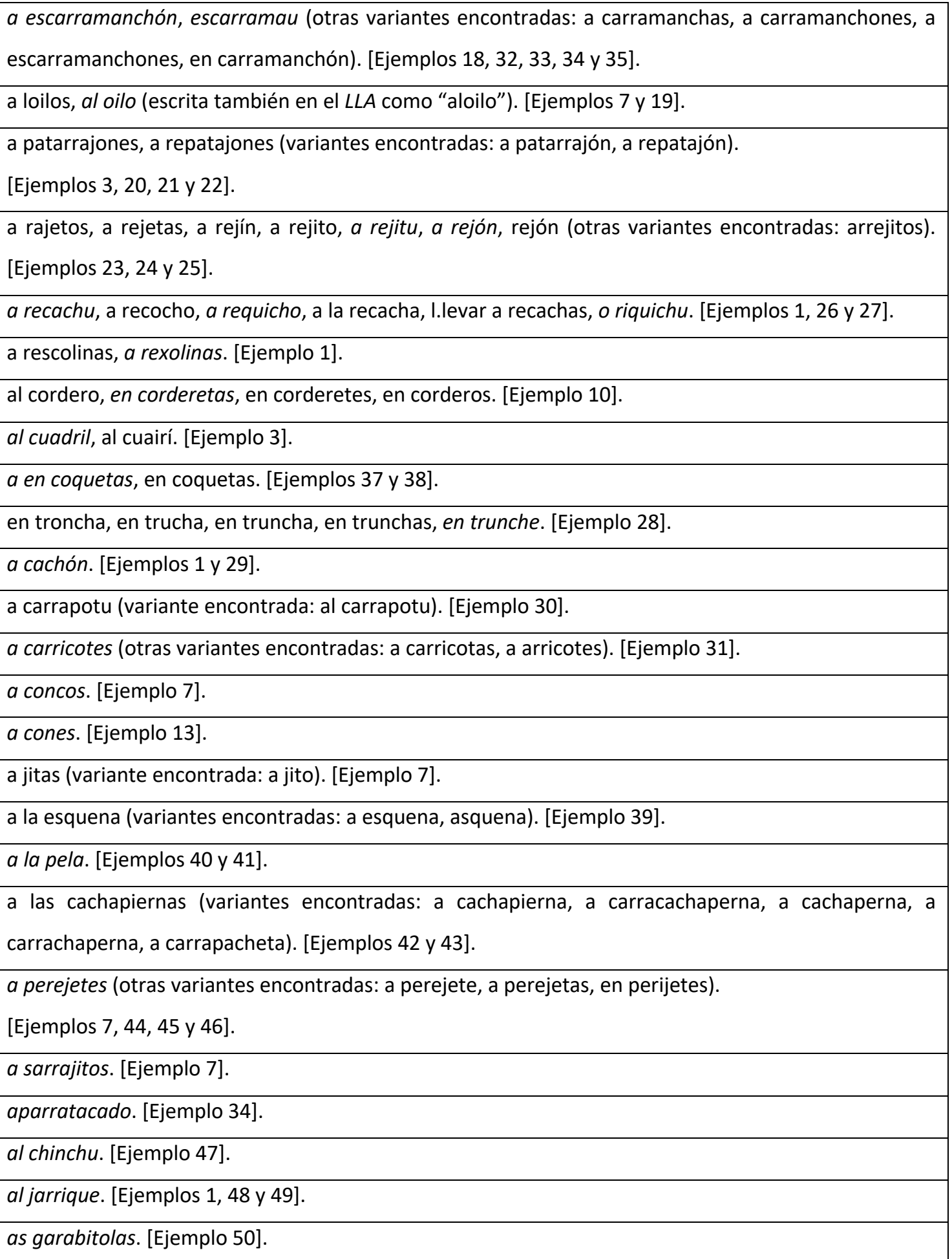

Tabla 3. Locuciones con el significado de 'llevar a cuestas' en el ALPI atestiguadas en fuentes secundarias.

1. Llevar a Cuestas. Torrebarrio: A cachón; Puente del Rey: 0 riquichu; Lillo del Bierzo: A las costiellas; Páramo del Sil: A las costietsas; Omañón: Llevalu aceite; Folledo: A rexolinas; Pontedo: A 
costinas; Cofiñal: A burras; Pío de Sajambre: Al jarrique; Laguna Dalga; A cuestas (Diario de León, 11/06/2016, https://www.diariodeleon.es/articulo/cultura/algunos-terminos/201606110400001603024.html).

2. aceites (llevar a) 1. Llevar a uno a cuestas. Del árabe záit, íd. (DECH, s. v. aceite). Zona de León: Murias de Paredes, Valle Gordo ([479], 270). Otras zonas: La expresión se usa en el noroeste de León y en Asturias [Alto Aller] con la misma acepción ([414], s. v. aceite) (LLA, https://lla.unileon.es/?id=EC100199).

3. LLEVAR A CUESTAS: a cuestas, a las costillas, a la espalda, a chon, a burricas, al cuadril, a burro, a la cadera, a repatajón, al chunchún (Llorente Pinto, María del Rosario: "Léxico disponible y léxico dialectal en la provincia de Ávila", en Luis Santos Río [coord.]: Palabras, norma, discurso: en memoria de Fernando Lázaro Carreter, 2005, págs. 681-694).

4. Cabrito. CABRITO (A). Alcalá Venceslada, Voc. And.: «A cabrito o a cabritos. A cuestas. «Le tuvo que llevar a cabrito hasta su casa». Rodríguez Marín, Cantos populares, 1, 121: «El niño montó...» (García de Diego, Vicente: Etimologías españolas, vol. I, Madrid, Aguilar, 1964).

5. Escarrapacharse. "Sentarse a horcajadas". ZAMORA. id. EI DRA, escarrancharse (Extrem., Zam., Sal.). En Olm., esparrancharse. Vid. esparrangarse (Fichero General de la Real Academia Española, https://webfrl.rae.es/fichero.html).

6. Escaparrachar. "Tender, extender" [Tf 41] (Fichero General de la Real Academia Española, https://webfrl.rae.es/fichero.html).

7. Se han documentado una serie de voces que no se han podido clasificar a causa del desconocimiento del origen de dichos vocablos: a sarrajitos, chamarco, a ricos, al siote, a jito, a churrejito, a chorta, richote, aposadillas, cuscus, jolio, barrandas, repatajón, concos, chico, pocha, pasiega, a perejetas, chon, chonchón (2), al oilo (2), camichocho*, trunche*, colicas*, cotenas* y chinchín*. No obstante, se ha hallado una posible explicación para la voz chinchín (rechinchín, a chinchines, a la chín) (Terrón Vinagre, Natalia: Variación léxica y semántica cognitiva: las designaciones de las actividades lúdicas en los atlas lingüísticos. Trabajo de Fin de Máster, Universitat Autònoma de Barcelona, 2015, p. 26-27).

8. Se refieren a este lenguaje [infantil]: tata f. 'hermana, prima, etc.', y tete m. 'hermano, primo, etc.', y llevar al chin o llevar al chinchin loc. 'llevar a un niño montado en la espalda o en los hombros de una persona', dicen: iqué bien va 'I chico 'l chin!, CHIN-, onomatopeya simbólica del movimiento del niño cuando la persona que lo lleva acelera el paso o corre (Nebot Calpe, Natividad: "Las voces naturales y la etimología popular en la toponimia y el habla del Alto Mijares y del Alto Palancia (Castellón)". Archivo de filología aragonesa, vol. 28-29, 1981, p. 57-82).

9. COTENAS. Llevar a uno a cotenas, ha sido sustituido por llevar a uno a corderetas o $a$ hombros. (Ablitas, Cortes)... (Marín Royo, Luis María: El habla en la Ribera de Navarra, Pamplona: Gobierno de Navarra, 2006).

10. La designación a/en cotenas, a pesar de aparecer como lema en el Diccionario de voces aragonesas (Borao 1859) y en el de Gaspar y Roig (1853), no se (sic) explica el origen de esta voz y en su 
Dialectologia. Special issue, IX (2021), 151-192.

ISSN: 2013-2247

definición remite a en corderetas y a horcajadas (Terrón Vinagre, Natalia: Variación léxica y semántica cognitiva: las designaciones de las actividades lúdicas en los atlas lingüísticos. Trabajo de Fin de Máster, Universitat Autònoma de Barcelona, 2015, p. 27).

11. COTETAS. "Cuestas" (Ilevar a) [Te 206]. V. colotas, cotanas (Fichero General de la Real Academia Española, https://webfrl.rae.es/fichero.html).

12. cucho $^{3}$. a cucho. 1. loc. adv. Cantb. a hombros (Real Academia Española: Diccionario de la lengua española, 23. a ed., [versión 23.3 en línea]. https://dle.rae.es).

13. CONES (A). García Lomas: "A cones. Vale por a cuchos en el valle de Soba.» RECHONCHÓN (A). Iribarren, Voc. Nav. (García de Diego, Vicente: Etimologías españolas, vol. I, Madrid, Aguilar, 1964).

14. A cucurumillo. Murc. mod. adv. fam. 'a hombros'. Se emplea ordinariamente refiriéndose a niños (García Soriano 36) (Pharies, David A.: Structure and Analogy in the Playful Lexicon of Spanish, Tübingen: Niemeyer, 1986).

15. Cucurumillo. Llevar al niño sobre uno de los hombros o despatarrado sobre los dos. En Álava, sonsaína (Sevilla, Alberto: Vocabulario murciano, Murcia: Imp. Sucesores de Nogué, 1919).

16. Cucurumillo: Llevar al niño sobre uno de los hombros o despatarrado sobre los dos (FIFITÚ, web sobre palabras andaluzas, https://fititu.es/definicion/cordoba-2/puente-genil/cucurumillo/).

17. A curumbillo. Esa expresión con sabor salobreñero, con aroma a infancia, de recuerdos asociados extrañamente a un día de romería de mi infancia. Estaba cansado, no quería caminar ya y mi padre me subió en sus hombros y me llevó durante un buen trecho. Ese instante no se me olvida; del mismo modo que no puedo olvidar la expresión "a curumbillo" ni muchas otras que demuestran la existencia de un lenguaje propio de la zona y los resquicios de algo que se perdió en el trajín de la historia de invasiones de esta tierra (http://elpapirodelaspalabrasliquidas.blogspot.com/2012/10/acurumbillo.html).

18. [...] en el Endize [de bocables de l'aragonés] escarramar(-se) 'separar las piernas; abrir, ensanchar las piernas', escarramau 'esparrancado; muy abierto de piernas' (Martí Mestre, Joaquim: "Afinidades léxicas aragonesas en el valenciano del siglo XIX". Archivo de Filología Aragonesa [AFA], no. 68, 2012, págs. 143-176).

19. oilo [oleo] 1. Aceite de linaza. Al oilo o aloilo, 'a cuestas' (LLA, https://lla.unileon.es/?id=EC111412).

20. PATARRAJÓN. -Se usa: a patarrajón, montar a horcajadas sobre una caballería (Madroñal Durán, Abraham: "Vocabulario y toponimia de la jara toledana", Anales toledanos, 22, 1986, págs. 211252).

21. Se trata de recopilar lo que un día fue esta tradición, y tomarlo como punto de partida hacia proyectos futuros vinculados al turismo nupcial en un entorno único, cuenta la próxima alcaldesa, que ha promovido un curioso diccionario del habla autóctona con dichos, coplillas y palabras típicas de Buenasbodas, como camocha (cabeza), embeleco (persona molesta), jarramantas (el que no da pie con 
bola) o patarrajón (cuando las mujeres se sentaban en el burro con una pierna a cada lado) (El Norte de Castilla, 27/06/2015).

22. patarrajón: De pata. Ir a patarrajón en una cabalgadura, es ir a horcajadas, es decir, una pierna a un lado y otra a otro. Forma muy expresiva. También se puede llevar a un crío a patarrajón en el cuadril, o sobre los hombros y el cuello, y lo contrario de a mujeriegas. En Herreruela se dice $a$ parrancas, como en Valladolid, registrado por el DRAE (García Sánchez, Julián: Cómo se habla en Lagartera (Serie Temas toledanos, n. 87). Toledo: Instituto Provincial de Investigaciones y Estudios Toledanos [IPIET], 1998).

23. arrejitos. Llevar arrejitos. Transportar a una persona a cuestas cabalgando sobre los hombros y el cuerpo erguido (García de Diego, Vicente: Etimologías españolas, vol. I, Madrid, Aguilar, 1964).

24. Las respuestas dadas en ambos lugares a las diez preguntas visibles en la web del ALPI son muy similares. Así, tanto en Espinama como en La Vega llaman "arvejas" a los guisantes; "catalina”, a la mariquita; "pisandera", al pájaro aguzanieves; "legartesa", a la lagartija; "escanillu", a la cuna; "hurmientu", a la levadura; y llevar a cuestas se dice "a rejitu" (Liébana en el Atlas Lingüístico de la Península Ibérica, http://www.valledeliebana.info/historias/alpi.html).

25. Salamanca: a rejón, 'a cuestas' ([308], 606) [...]; Burgos [Bureba]: a rejón, 'a coscas; suele decirse del modo de llevar a hombros un niño, con las piernas hacia delante' $([246], 101,193)(L L A$, s. v. rejón, https://lla.unileon.es/?id=EC113599).

26. A recachu. [Pr.]: '(llevar un peso) sobre los hombros en la espalda' [Pr (= a la recachina).]. A hombros (García Arias, Xose Lluis: Diccionario General de la Lengua Asturiana (DGLA), Uviéu: Editorial Prensa Asturiana, 2020, https://mas.Ine.es/diccionario/palabra/63060).

27. María Concepción Fernández López proporciona más datos. Confirma lo de "a coscoletas" en Navarra, "a requicho" en Galicia, "o carracho" en Lugo. Lo de "coscoletas" lo identifica con "caracoles" (Ilevan la casa a cuestas) y "carracho" equivale a "garrapata" (Miguel, Amando de: "Frases que no hacen historia", Libertad Digital, 16/05/2005).

28. Capitejo, En. Se dice cuando una persona monta a otra sobre los hombros. La variedad de montar sobre las espaldas de otro se conoce como ir en trunche.

En Trunche. Manera de transportar una persona a otra enganchándose el montado en la espalda del montador y éste sujetándole por el trasero. Lo suele practicar el padre con el hijo pequeño cuando éste, después de haber estado toda la tarde de pie por la Feria, Semana Santa, etc., pide a aquél: "Papá, estoy mu cansao, montame en trunche" (Vocabulario popular de Valverde del Camino, Huelvapedia, https://huelvapedia.wikanda.es/wiki/Vocabulario_popular_de_Valverde_del_Camino).

29. LOCALIZACIÓN: Bierzo (García Rey, 1979, 59). Cachón, 'corriente impetuosa y rápida de los ríos o presas, que después se sosiega en las tabladas y en los pozos'; a cachón, 'borbotón del agua al hervir'; llevar a cachón (Jeannick Le Men Loyer: Léxico del leonés actual, vol. II, León: Centro de Estudios e Investigación San Isidoro, 2002). 
30. Nesta llista apaecen frases feches, locuciones, xiros y otres espresiones idiomátiques en castellanu con delles de les equivalencies posibles n'asturianu.

A hombros, al hombro, en hombros: a recostín, al recostín, a recostines, al costín, a los costinos, a costinos, al costazu, a los costazos, a carranquina, a la carranquina, al carrapotu, al carrapote, a carrapochu, al carrapochu, a carrapucha, a les carrapuches, a carrapuchu, al carrapuchu, a carraputu (Espaciu y tiempo de la llingua asturiana, https://asturies.com/espaciuytiempu/deprendiasturianu/bilordiosfiloloxicos/espresiones-idiomatiques-iii).

31. Carricotas, a..., m. adv., "llevar a cuestas o sobre los hombros". En Álava a arricotes "id." (BARAIBAR, LÓPEZ DE GUERENU); éste último recoge además en Albaina, Treviño, a carricotes (Sánchez González de Herrero, María Nieves: El habla y la toponimia de la Puebla de Arganzón y el Condado de Treviño, Vitoria: Diputación Foral de Álava, 1985). (Fuente: Google).

32. La señora Bárbara se imaginaba que la ayudaba a subir a una yegua blanca un joven elegido entre los amigos de su novio. Por primera vez en su vida montaba en una silla, a la mujeriegas, y no a escarramanchón, como le había tocado ir siempre encima de una albarda (https://letrasdesdemocade.com/2020/03/02/la-tornaboda-de-barbara-de-farasdues/).

33. carramanchas o carramanchones. A carramanchas [carramanchones] (Aragón). Se aplica a la manera de *llevar una persona a otra, bien sobre los hombros con una pierna pasada por cada lado del cuello o bien sobre el lomo o una cadera con una pierna a cada lado del cuerpo. (T. "A escarramanchones". V. "a *Cuestas, a *horcajadas" (Fichero General de la Real Academia Española, https://webfrl.rae.es/fichero.html).

34. Este grupo léxico-semántico está compuesto por una serie de unidades pluriverbales y verbos que describen la postura que la persona transportada adquiere en el juego [...] Así, las voces que se encuentran en este grupo significan 'abrirse de piernas': escarranchado, anchagarras, escarranjado, da (llevarlo escarranjado) esparrancarse (esparranquillas, esparragado, aparratacado) y espatarrado; o 'con una pierna a cada lado de donde se está sentado': a horcajadas, a bomborombillos, a cucurumbillos, a escarramanchones, a carramanchones, escarramado y los derivados de a parrancas, perrancachón y palancadillas (Terrón Vinagre, Natalia: Variación léxica y semántica cognitiva: las designaciones de las actividades lúdicas en los atlas lingüísticos. Trabajo de Fin de Máster, Universitat Autònoma de Barcelona, 2015, págs. 26-27).

35. Carramanchón (en). Félix Huerta Tejadas lo recoje (sic) de Navarra: “En carramanchón. Subido por detrás y agarrado por el cuello" (Fichero General de la Real Academia Española, https://webfrl.rae.es/fichero.html).

36. Todos conocemos perfectamente el significado de esta palabra. Sabemos que decir montar, sentar a horcajadas o cabalgar, es más fino, pero la palabra aparratacar, es una de las joyas de nuestras expresiones, y es que define perfectamente cuando alguien se sienta con las piernas abiertas sobre algo. Además, parece que le da hasta un significado de coraje, de temperamento, cuando se dice: "Se aparratacó y dijo que de allí no se bajaba ni aunque se lo pidiera el papa en persona" 
(https://www.facinas.org/hemeoreteca/2012/2012\%20pdf/8\%20octubre\%202012.pdf, Facinas Digital, 08-10-2012, Facinas [pedanía de Tarifa, Cádiz]).

37. A encoquetas. (loc. adv.) Forma de llevar a alguien sobre la espalda, agarrándose a los hombros. (Lu,) (Dizionario aragonés de las comarcas de la de la Alta Zaragoza, http://www.charrando.com/docs/lesicoaltazaragoza.pdf).

38. COCHETAS. "Hombros" (llevar a) [Hu 100]. V. coleCAS, coletAS, Collas, colletAs, colletes, coquetas, cotenas, cotetas, cullecAs (Fichero General de la Real Academia Española, https://webfrl.rae.es/fichero.html).

39. k) Esquena "lomos, costillas". ASQUENA. En parte de Cataluña y Valencia por "a cuestas". ESQUENA (A) (García de Diego, Vicente: Etimologías españolas, vol. 1, Madrid: Aguilar, 1964).

40. Es importante señalar que, a pesar de destacar el color amarillo en La Rioja, Burgos y Cantabria, además de nombres de animales, también se hallan vocablos relacionados con montar a caballo (jineta, a rejón, etc.). Lo mismo ocurre en la isla canaria del Hierro, donde la designación más habitual y productiva es a la pela (estilo de montar a caballo § 4.2.2.1) (Terrón Vinagre, Natalia: Variación léxica y semántica cognitiva: las designaciones de las actividades lúdicas en los atlas lingüísticos. Trabajo de Fin de Máster, Universitat Autònoma de Barcelona, 2015, pág. 28).

41. La pela no se refiere a la peseta, que es algo mucho más moderno, sino que antiguamente la expresión "Ilevar a la pela" era "llevar a hombros", como vemos en Galdós cuando nos dice "un tío en pelota que le llaman Eneas, con su padre a la pela", refiriéndose a un cuadro en donde Eneas huye de Troya con su padre a cuestas. Por eso "bailar la pela" se refería a que el hombre bailaba con el niño a hombros, "a la pela". (https://raicesdeperaleda.com/diccionario/bailar/p-1996).

42. Hay locuciones adverbiales modales como al dereitu, abondu, a modu, da furtu ("a escondidas"), dafeitu, aposta, a cachapierna ("montado a lomos de alguien"), a trincacarnela ("dando vueltas de cabeza"), en cárnicas ("en cueros") (Álvarez López, Alejandro: El burón. La jerga de los vendedores y albarderos ambulantes de Forniella. Uviéu: Instituto de Estudios Bercianos y Academia de la Llingua Asturiana, 2005).

43. carracachaperna (llevar a-) [cachaperna | carrachaperna | carrapacheta]. 1. Llevar a horcajadas. 2. Llevar a un niño o muchacho al hombro con una pierna por cada lado del cuello. Forma expresiva hecha sobre carraca, cacha y perna. Zona de León. Bierzo: Ancares (LLA, https://lla.unileon.es/?id=EC103233).

44. perejetes. a . 1. loc. adv. m. 1. a cuestas (Montar) a la espalda. [PCVM: Menaza.] Llevaba siempre a su sobrino cargado a perejetes. [AYVB: Barruelo.] Tan terco me ponía que, más de una vez, mi madre me llevó y me trajo a perejetes. [NSAM: Barruelo.] [CFEV: Barruelo.] (Vielba Porras, Carlos: EI léxico de la montaña palentina, 2011, pág. 528). (Fuente: Google).

45. a perejete. - llevar a alguien sobre los hombros. Vide: a rejitu. (Wikcionario Cantabru).

46. Perijetes. (llevar en); a perejetes. Locución para indicar que se llevaban los niños en los hombros, a cuestas (Fernández Manjón, José María y Desiderio Fernández Manjón: Las palabras y el 
contexto. El habla de las loras de Burgos y su entorno, Madrid: Asociación Cultural y Científica Iberoamericana, 2014).

47. chinchu: I| Al chinchu, en llombu. ¿Llévasmi al chinchu? (Rodríguez Corao, Ramón: Vocabulariu de Ruenes (El Valle Altu de Peñamellera). Uviéu: Academia de la Llingua Asturiana, 2011).

48. JARRIQUE. 'Llevar al jarrique es llevar a uno a la espalda, sentado sobre los hombros'. G. LOMAS, jarajicho, a cuchi, etc. 206; MENÉNDEZ GARCíA, en BIEA XXV, 261 (el columpio en ast.) cita un jarricase 'columpiarse en un madero', en Peñamellera Baja. Creo que ambos se relacionan (Fichero General de la Real Academia Española, https://webfrl.rae.es/fichero.html).

49. JARRIQUE (AL). Al jarrique. adv. Manera de llevar una persona a otra, ésta puesta sobre las espaldas de la primera, con los brazos sobre sus hombros rodeándole el cuello, las piernas encogidas o levantadas hacia adelante rodeando la cintura de quien la lleva, la cual suele coger con las manos las piernas o los pies de la otra. Se lleva así comúnmente a los niños (Fichero General de la Real Academia Española, https://webfrl.rae.es/fichero.html).

50. Tamén existen as locusióis adverbiales. Dalgúas das mais usadas son estas que siguen:

De modo: ás garabitolas... (Normas ortográficas del gallego-asturiano, Uviéu: Academia de la Llingua Asturiana, 2007).

Como señalábamos anteriormente, en algunas ocasiones las formas registradas en el $A L P I$ coexisten, en lo que se refiere a documentación, con otras que introducen pequeñas modificaciones respecto de aquellas. Tal vez se hayan desarrollado nuevas variantes o algunas de ellas no fueron registradas en el $A L P I$ en su momento:

- Singular / plural: a aceite (ALPI) / a aceites; a cabrito (ALPI) / a cabritos; a chinchín (ALPI) / a chinchines; a cucho (ALPI) / a cuchos; a escarramanchones (ALPI) / a escarramanchón; a jitas $(A L P I)$ / a jito; a rejito (ALPI) / arrejitos; a patarrajones (ALPI) / a patarrajón; a perejetes (ALPI) / a perejete; a repatajones (ALPI) / a repatajón; a las cachapiernas (ALPI) / a cachapierna - a cachaperna.

- Cambio de timbre vocálico: a cucho - a cuchu (ALPI) / a cuchi; cotenas (ALPI) / cotanas; esquena (ALPI) / asquena; perejetes (ALPI) / perijetes.

- Otras modificaciones: a carrapotu (ALPI) / al carrapotu; a burras (ALPI) / a burricas; a carricotes (ALPI) / a arricotes; a cucurumillo - a curumbillo (ALPI) / a cucurumbillos; a escarramanchón (ALPI) / a carramanchones - en carramanchón - a escarramanchones; a perejetes (ALPI) / en perijetes; a la esquena (ALPI) / a esquena; a las cachapiernas (ALPI) / a carracachaperna - a carrachaperna-a carrachapeta. 
Por otro lado, algunos de estos ejemplos permiten ampliar o bien actualizar el alcance geográfico reflejado en el $A L P I$ a propósito de algunas de estas UF, y del que se dio cuenta en páginas anteriores:

- Aparratacado: Cádiz

- Arrejito: Cantabria

- A aceites (ALPI: a aceite, llevarlu aceite): zona de León: Murias de Paredes, Valle Gordo. Otras zonas: noroeste de León y Asturias [Alto Aller].

- A burro: Ávila

- A coscoletas: Navarra

- A cotenas: Navarra

- A patarrajón (ALPI: a patarrajones): Toledo

- A perejete (ALPI: a perejetes): Cantabria

- A rejón: Salamanca, Burgos (Bureba)

- A repatajón (ALPI: a repatajones): Ávila

- Al cuadril: Ávila

- A la espalda: Ávila

- A las costillas: Ávila

- Cucurumillo: Andalucía

- En perijetes (ALPI: a perejetes): Burgos

Además, en los testimonios procedentes de FS (fundamentalmente en los trabajos de Llorente Pino [2005], Terrón Vinagre [2015], LLA y Fichero General de la RAE) se registran locuciones con el significado de 'llevar a cuestas' no recogidas en el ALPI: chamarco, a churrejito, a chorta, a coscas, a la cadera, a la recachina, aposadillas, al siote, barrandas, camichocho, chico, cuscus, o carracho, pocha, pasiega, sonsaína.

Por último, hay UF atestiguadas en lo que hemos catalogado como fuentes primarias (FP), denominación que alude a los textos orales y escritos ajenos al ámbito metalingüístico. ${ }^{10}$ Muchas de ellas comparten origen y por eso hemos optado por presentarlas agrupadas, lo cual no significa que todas ellas aparezcan en FP y ni

\footnotetext{
${ }^{10}$ Esto no significa, obviamente, que no puedan aparecer también en diccionarios o en trabajos de carácter científico y académico.
} 
Dialectologia. Special issue, IX (2021), 151-192.

ISSN: 2013-2247

siquiera en FS, pues de bastantes no hemos encontrado testimonio alguno si nos atenemos a la forma exacta registrada en el ALPI. En cualquier caso, si están incluidas en la tabla que sigue es porque una de las formas con las que están emparentadas o relacionadas tiene al menos una ocurrencia en una FP, lo cual permite contar con usos más prototípicos que los metalingüísticos. Hemos escrito en ella en redonda las variantes del $A L P I$ de las que no hay documentación si nos atenemos a su literalidad; en cursiva, aquellas de las cuales hay documentación en FS; y hemos incluido, como en la tabla 3 , otras variantes encontradas cuando se ha dado el caso. Asimismo hemos escrito en negrita las que están documentadas en FP:

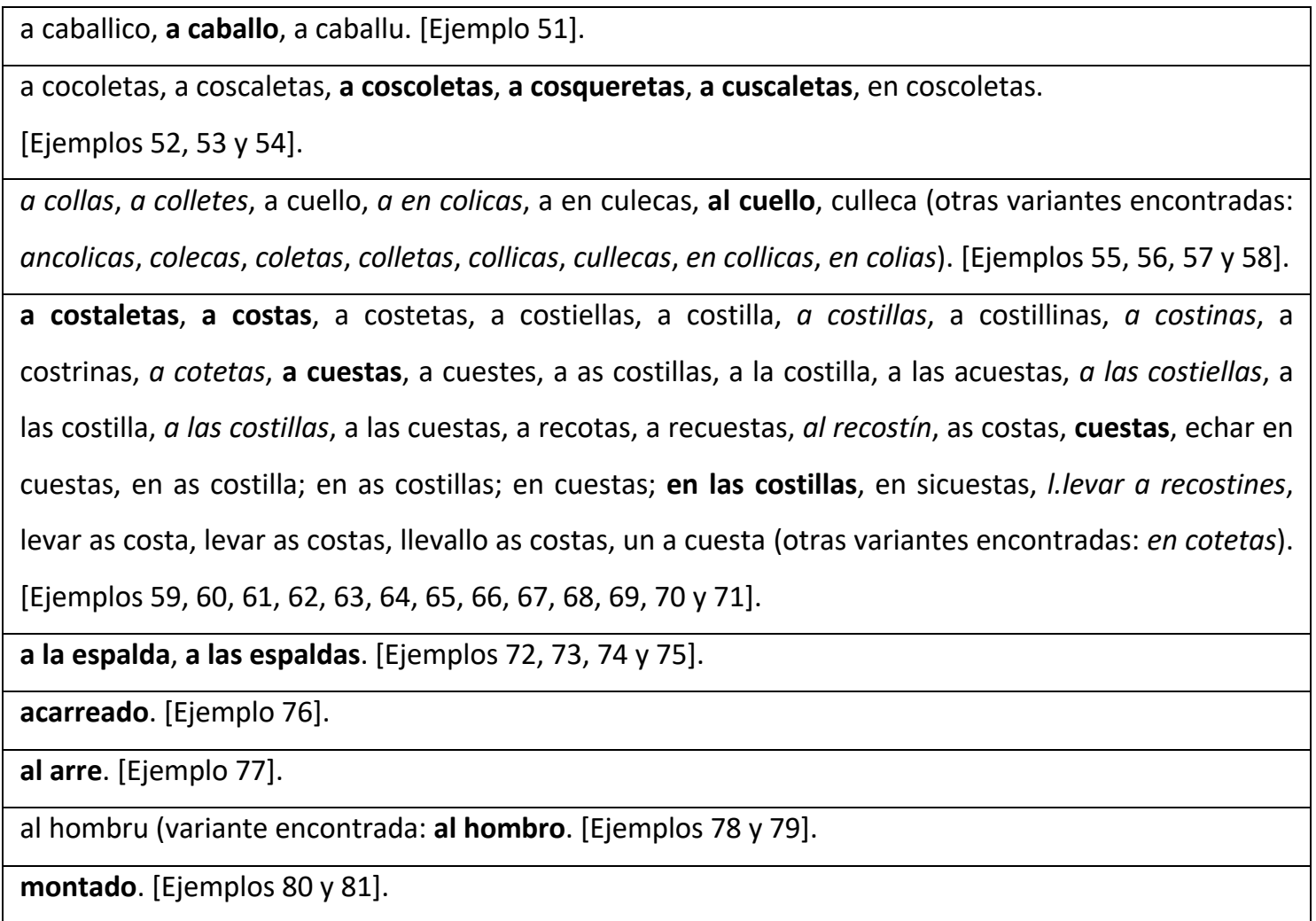

Tabla 4. Locuciones con el significado de 'llevar a cuestas' en el ALPI atestiguadas en fuentes primarias y secundarias.

51. Dos hombres colgados hacen de semáforos rojo y verde. El tráfico son hombres llevando a caballo a otros. Entra en un edificio y el contrapeso del ascensor es un hombre muy gordo (44 cortos para pensar la vida - Pan y Rosas, http://panyrosas.es/youtubes.html. País: España). (Fuente: CE).

52. Estaba en un tercer piso de la calle Eulogio Serrano, se rompía el ascensor continuamente y había que subir 'a coscoletas' a los críos... (Tendría que estar toda la vida dándole 
gracias a la gente de Murcia, http://www.laverdad.es/murcia/v/20130822/local/region/tendria-estar-toda-vida201308200053.html. País: España). (Fuente: CE).

53. Una pareja de adolescentes de la Escuela de Circo de Shanghai presentó un espectacular número de barra rusa que proporcionó momentos de tensión como éste: llevando el chico a cosqueretas a la chica y sin deshacer esa frágil figura, se libraron una secuencia rítmica de saltos mortales sobre la barra, que remataron con una espléndida doble pirueta invertida (Jané, Jordi: “Circo de élite en Montecarlo". Artez. Elorrio: Alter blai Kultur Elkartea, 01/02/2003. País: España). (Fuente: CORPES XXI).

54. Eso decían cuscaletas. Se montaban a cuscaletas 11 y ya te montaba el otro y si no te $\mathrm{m}$ ontaba el otro lisiao. A jugá otra vez. Ganabas tú, pos entonces [HS:I1 O pescazones.] tú te montab as | o pescazones... (Enclave: Palacios Blancos [Lorquí], Murcia, COSER-3111_01).

55. Lo mismo ocurre con la denominación colicas (en collicas, ancolicas, en colias), también incluida como lema en Endize de bocables de l'aragonés, II (1999): Colicas (en). 'ir un niño sobre la espalda de otro' (Terrón Vinagre, Natalia: Variación léxica y semántica cognitiva: las designaciones de las actividades lúdicas en los atlas lingüísticos. Trabajo de Fin de Máster, Universitat Autònoma de Barcelona, 2015, pág. 27).

56. COlOtAS. "Cuestas" (llevar a). [Hu 202]. V. colletAs, collicas, coquetas, cosquetAs, costetas, cullecas, cotetas (Fichero General de la Real Academia Española, https://webfrl.rae.es/fichero.html).

57. ¡Hombre!, algún día a lo mejor mi madre me los tenía, pero como también ella se trabajaba, pues no me lo podía tener nada más yo siempre los llevé con las ovejas, por el invierno con buen frío llevé los niños al cuello y los llevé a arar, a arar, como dije, a arar con las vacas y los llevé a segar el pan cuando segábamos el trigo y el centeno y todo eso (Enclave: Lucillo, León, COSER-2644_01).

58. COCHETAS. "Hombros" (llevar a) [Hu 100]. V. coleCAS, coletas, collas, colletas, colletes, coquetas, cotenas, cotetas, cullecas (Fichero General de la Real Academia Española, https://webfrl.rae.es/fichero.html).

59. Y dice la zorra, la muy gandula: - Me tienes que llevar a costaletas, que yo no puedo andar. Y entonces se la echó a costaletas12 (Hernández Fernández, Ángel: Cuentos populares de la provincia de Albacete, vol. 124 de serie I, Albacete: Instituto de Estudios Albacetenses "Don Juan Manuel", 2001).

60. Me refiero a que si una mujer a pesar de ser mayor es poco quejosa y sexualmente bastante exigente por muy joven que este un hombre lo va a satisfacer y claro si tiene la suerte de encontrar un hombre que dentro de todo no es mujeriego y si sea respetuoso la desventaja es la

\footnotetext{
${ }^{11}$ Nótese que a cuscaletas aparece combinado con el verbo montarse, y no con llevar.

12 Nótese el uso de echar junto a costaletas en esta ocurrencia, además de llevar.
} 
que enfrentan socialmente, ya que tienen que enfrentarse a críticas unas prodentes otras imprudentes y les toca llevar a costas este tipo de situaciones (Las diferencias de edad - Toda Mujer es Bella, http://www.todamujeresbella.com/5721/las-diferencias-de-edad/. País: México). (Fuente: $\mathrm{CE}$ ).

61. (Si) Cotazo. (adj.) Compacto, duro, endurecido, apelmazado, compactado. (Ar, Lo, Lu, Mo, F, M, Si, B, Fu, P, O, S) Cotetas. En cotetas. (adv.) Modo de llevar a uno sobre los hombros con un pie a cada lado de la cabeza (Romanos Hernando, Fernando: Al límite: la pervivencia del aragonés en las comarcas del norte de Zaragoza, volumen 4 de la colección Martín Cortés, Zaragoza: Diputación de Zaragoza, 2003).

62. COTETAS. "Cuestas" (llevar a) [Te 206]. V. colotas, cotanAs (Fichero General de la Real Academia Española, https://webfrl.rae.es/fichero.html).

63. COTETAS [EN]. "hombros" (Ilevar a). [Na 600]. V. cochetAS (Fichero General de la Real Academia Española, https://webfrl.rae.es/fichero.html).

64. Villadepera de Sayago: Ilevar a costillas (Borrego, 1981, 207); Sal. (Re-bollar): costillas, "Ios dos palos que van a cada lado de las gamellas en el yugo de burros" (Iglesias, 1990, 112) (Jeannick Le Men Loyer: Léxico del leonés actual, vol. II, León: Centro de Estudios e Investigación San Isidoro, 2002).

65. LleVAR A CUESTAS. Torrebarrio: A cachón; Puente del Rey: O riquichu; Lillo del Bierzo: A las costiellas; Páramo del Sil: A las costietsas; Omañón: Llevalu aceite; Folledo: A rexolinas; Pontedo: A costinas; Cofiñal: A burras; Pío de Sajambre: Al jarrique; Laguna Dalga; A cuestas

(Diario de León, 11/06/2016, https://www.diariodeleon.es/articulo/cultura/algunosterminos/201606110400001603024.html).

66. Cómo nos iba a llevar a los tres a cuestas a nosotros, no podía ser (Enclave: Almajano, Soria, COSER-3901_01).

67. Cuando usted lea lo que le sucede a otras personas que están pasando por situaciones similares a las de usted, se dará cuenta inmediatamente de que la cruz que lleva a cuestas, no es tan pesada (Palabras que fortalecen para llenar tu corazón de ánimo y alegría, http://blog.beliefnet.com/palabrasquefortalecen/. País: Estados Unidos). (Fuente: CE).

68. LLEVAR A CUESTAS: a cuestas, a las costillas, a la espalda, a chon, a burricas, al cuadril, a burro, a la cadera, a repatajón, al chunchún (Llorente Pinto, María del Rosario: “Léxico disponible y léxico dialectal en la provincia de Ávila", en Luis Santos Río [coord.]: Palabras, norma, discurso: en memoria de Fernando Lázaro Carreter, 2005, págs. 681-694).

69. A recostinas se documenta en la montaña centro-oriental leonesa y en Asturias [Santianes de Pravia] [en otros pueblos: al recostín, a recostines, al xacostín, etc. ] ([414], s. v. cuestas) (LLA, https://lla.unileon.es/?id=EC113470). 
70. Aqui en Bolivia aun es tenue la intension de despertar creo que por los problemas sociales que la mayoria de la gente lleva cuestas cada dia... pero quiero ser parte de la Dufusion... (Blog Soy lo suficientemente inteligente para saber que soy idiota, http://contraperiodismomatrix.com/soy-lo-suficientemente-inteligente-para-saber-que-soyidiota/). (Fuente: CE).

71. Descartado el ir a tu escritorio cuando no estés, no vaya a ser que me ladres... Y ahora para acabar de frustrarme, me dirás que eres autodidacta. Que nunca pisaste salón de clase y que yo boté mi dinero (y sigo botándolo pues el préstamo estudiantil aún lo llevo en las costillas) (blog Puerto Rico, Rangely García: La Caballota de la @tripleta UNDOdigital.com, http://undodigital.blogspot.com/2012/01/rangely-garcia-la-caballota-de-la.html). (Fuente: CE).

72. Una vez me acuerdo que, que no quería ir yo a la escuela y mi madre me llevó... a la espalda me llevó a Torrebaja a la escuela, ya lo creo (Enclave: Mas de los Mudos, Castielfabib, Valencia, COSER-4301_01).

73. El peso no hace más que crecer. La carga que se lleva a la espalda aumenta a cada momento (blog Horoscopia: Para ser feliz deja atrás lo aprendido, http://horoscopia.blogspot.com/2013/04/para-se-feliz-deja-atras-lo-aprendido.html. País: Venezuela). (Fuente: CE).

74. Nosotros teníamos un pastor, [Rndo: que se lo voy a contar] [RISA], que yo decía --- se echaba la merienda en un zurrón, que e-..., como ahora llevan los bolsos esos que llevan a las espaldas, así lo llevaba el pastor (Enclave: Puebla de Don Fadrique, Granada, COSER-1832_01).

75. Un lugar curioso y atractivo, donde sí paseamos un poco y estiramos las piernas después del largo viaje que llevábamos a las espaldas (blog Carretera y abismos / Chinchetas en un mapa, http://www.chinchetasenunmapa.com/2012/01/carretera-y-abismos.html. País: Bolivia) (Fuente: CE).

76. Lo que Consuelo llevaba acarreado en la enfermedad que vino padeciendo sin que nadie se percatara, y sin que ella diese otra muestra de la misma que la del agotamiento en algunas tardes, cuando al regresar a casa caía derrotada en una silla o en la cama o en el mismo suelo sin poder llegar a la habitación, era casi el total de lo que llevaba acarreado en la vida desde su matrimonio (Díez, Luis Mateo: "La escoba de la bruja", Los frutos de la niebla, Madrid: Alfaguara, 2008). (Fuente: CORPES XXI).

77. Sí. A un eje, [HS:E1 [Asent].] a un eje que tenía pues, pues, pues, pues una rueda aquí y otra allí, bien, todo bien preparao, que era con los que los bueyes se te I se acarreaba todo, se llevaban todos los productos al arre, a todos los sitios (Enclave: Olmos de Ojeda, Palencia, COSER3414_01). 
78. Sí, señor. En la ermita hay una virgen grandiosa, que pesa muchísimo y ahora... la han pr eparao un carro o eso que va... que la llevan sin tener que llevala al hombro, pero si no, es para Ilevala al hombro, era pesada (Enclave: Puebla de Arenoso, Castellón, COSER-1310_01).

79. No, no, pagar, no. Los chicos de la congregación llevaban al hombro a san Luis, por ejemplo (Enclave: Leitza, Navarra, COSER-3214_01).

80. Y por más que me ponga de puntillas, ino veo mi cara en el espejo del baño! Por eso, ¡cómo me gusta cuando mi papi me lleva montado sobre sus hombros! (Cuento Infantil Cuando sea grande - Cuento cuentos, http://www.cuentocuentos.net/cuento/1796/cuando-sea-grande.html. País: España). (Fuente: CE).

81. - Yo no voy, tío Tigre. ¿Meterme esa caminada ahora, con este desaliento? El tigre se quedó como cavilando, y dijo: - Si es eso, tío Conejo, camine, yo lo llevo montado hasta allá. El conejo decía que no, que estaba muy maluco, y el tigre insistía en que fuera. Hasta que el conejo dijo: - Bueno pues, tío Tigre. Yo sí voy, pero con una condición: que usted me lleve montado y me vuelva a traer a la casa (EI rey de los animales - Secretos Para Contar, http://www.secretosparacontar.org/Lectores/Contenidosytemas/Elreydelosanimales.aspx. País: Colombia). (Fuente: CE).

Si bien la aparición de estas locuciones en FP nos proporciona contextos de uso mucho más completos que los de las FS, lo cierto es que estas últimas, como ya se señaló con anterioridad, permiten detectar no pocas variantes, en este caso: ancolicas, colecas, coletas, colletas, collicas, cullecas, en collicas, en colias o en cotetas. Y tanto las FP como las FS nos permiten en ocasiones ampliar o actualizar el alcance geográfico de las formas presentes en el $A L P I$. Así, al arre aparece registrada en el $A L P I$ en Asturias (Nozaleda), mientras que en el COSER su única ocurrencia remite a Palencia (Olmos de Ojeda); y a cotetas está atestiguada en el $A L P I$ en Navarra (Uscarés), mientras que en cotetas, en la FS correspondiente, está vinculada a Zaragoza.

Por otro lado, el hecho de que estas UF figuren en fuentes primarias no está relacionado necesariamente con una alta frecuencia de uso, si bien es cierto que las más frecuentes se encuentran en este grupo. Mientras a caballo, a cuestas, a la espalda, a las espaldas, acarreado o montado presentan un empleo bastante extendido tanto en el español europeo como en América, ${ }^{13}$ otras como a coscoletas, $a$

\footnotetext{
${ }^{13} \mathrm{Si}$ tomamos como referencia el $\mathrm{CE}$, llevar a caballo está documentado en un total de 11 países: Argentina, Bolivia, Chile, Colombia, Cuba, España, Estados Unidos, Honduras, México, Puerto Rico y Venezuela. Llevar a cuestas, en 21: Argentina, Bolivia, Chile, Colombia, Costa Rica, Cuba, Ecuador, El
} 
cosqueretas, a costaletas, a costas, a cuscaletas, al arre, al cuello y en las costillas cuentan con muchos menos testimonios. Las primeras, de hecho, están incluidas en el $D L E$ de la RAE, a diferencia de las segundas. Por último, es fácilmente constatable que son las UF más frecuentes y extendidas las que suelen desarrollar usos figurados (ejemplos 60, 67, 71, 73, 75 y 76).

\section{Conclusiones}

A lo largo de las páginas anteriores se ha presentado un estudio sobre la locución llevar a cuestas y sus variantes registradas en el ALPI. Para ello hemos partido de la pregunta 751 del citado atlas lingüístico, que indaga justamente sobre esta expresión y de la que hay 157 variantes (una vez excluidas las de los dominios catalán y gallegoportugués) entre 576 respuestas. Puesto que la información procedente del ALPI fue recabada en los años 30 de la pasada centuria, hemos confrontado dicha información con la situación actual.

Para nuestra investigación hemos optado por la búsqueda combinada en un corpus oral rural (COSER) y dos de referencia (CORPES XXI y CE), así como en Google, puesto que nos interesa conocer su grado de instauración en los corpus y en la Red (en futuros trabajos se abordará el estudio de estas UF en los atlas lingüísticos posteriores). Su consulta nos ha permitido extraer las siguientes conclusiones:

1. Hay 22 formas (de 157: 14,01 \%) recogidas en el $A L P I$ que no encuentran documentación en ninguna de las fuentes manejadas ni parecen estar ligadas a otras variantes sí atestiguadas. Las causas de este hecho pueden hallarse en que su uso se está reduciendo cada vez más (variación diacrónica), si bien no ha de descartarse que el alcance geográfico restringido de bastantes de estas locuciones lleve a evitar su utilización ante hablantes no autóctonos (en lo referente a un corpus oral rural como

\footnotetext{
Salvador, España, Estados Unidos, Guatemala, Honduras, México, Nicaragua, Panamá, Paraguay, Perú, Puerto Rico, República Dominicana, Uruguay y Venezuela. Llevar a la espalda, en 13: Argentina, Bolivia, Chile, Colombia, Cuba, España, Estados Unidos, Honduras, México, Nicaragua, Paraguay, República Dominicana y Venezuela. Llevar a las espaldas, en 7: Colombia, España, Estados Unidos, Guatemala, Honduras, México y Uruguay. Llevar acarreado, en 4: Colombia, Chile, España y México. Y Ilevar montado, en 4: Colombia, España, República Dominicana y Venezuela.
} 
el COSER) o a incluirlos en textos escritos. ${ }^{14}$ Tampoco que las preguntas formuladas a los informantes puedan favorecer más o menos la inclusión de cierto léxico dialectal en sus respectivas alocuciones, o que las UF en cuestión (o algunas de ellas) formen parte de un léxico pasivo que las generaciones más jóvenes entienden, pero que no utilizan habitualmente.

2. Un buen número de UF se encuentra atestiguado únicamente en lo que hemos catalogado como fuentes secundarias, es decir, en documentos de carácter científico-académico, diccionarios u otros repertorios lexicográficos, blogs y foros. Se trata de contribuciones que dejan constancia de la existencia de tales UF, de varias de sus características, de unidades léxicas y variantes fonéticas no registradas en el ALPI y que posibilitan ampliar o actualizar la distribución espacial de algunas de ellas; no obstante, no permiten constatar su frecuencia de uso entre los hablantes ni reflexionar sobre los contextos en los que se utilizan o sobre sus significados en una secuencia concreta. También son buen indicio del interés que suscitan como léxico identitario.

3. Entre estas UF hay variantes del ALPI no documentadas si nos atenemos a su literalidad, pero que presentan pocas variaciones respecto de otras formas registradas en las FS: singular / plural; cambios de timbre vocálico u otras modificaciones (presencia o ausencia de artículo, uso de preposiciones distintas, etc.). A veces no hemos encontrado testimonios de determinadas formas, pero sí de otras con las que comparten origen o parecen estar relacionadas. Asimismo el rastreo en las FS nos ha permitido detectar otras locuciones que expresan el significado 'llevar a cuestas'.

4. Hay ocurrencias de UF que figuran en contextos distintos a los metalingüísticos (fuentes primarias), lo cual puede favorecer, en algunos casos, la transposición de usos rectos a figurados. En este grupo cabe situar las UF de empleo más frecuente (a caballo, a cuestas, a la espalda, a las espaldas, al hombro, acarreado y montado), si bien esto no significa que en este tipo de fuentes no haya expresiones con poca documentación (a coscoletas, a cosqueretas, a costaletas, a costas, a cuscaletas, al arre, al chinchín, al cuello y en las costillas). Cabe resaltar el hecho de que las primeras están incluidas en el $D L E$, no así las segundas.

\footnotetext{
${ }^{14}$ Vid. en el apartado 1 (“Introducción”) la cita de Fernández-Ordóñez (2007: 31).
} 
Por último, ha quedado demostrado que la fraseología es uno de los exponentes más claros de la variación diacrónica y diatópica. De ahí la importancia de conocer su comportamiento en los diversos países hispanohablantes, pero también en los ámbitos rurales, excluidos a menudo del análisis de los investigadores. En este sentido, contar con atlas lingüísticos ( $A L P I$ y los atlas lingüísticos posteriores), corpus orales rurales (COSER) y otros tipos de corpus, documentos y herramientas ayuda sobremanera a trazar la distribución geográfica y uso de determinadas unidades léxicas, en nuestro caso, las unidades fraseológicas.

\section{Referencias}

Bernat I Baltrons, Francesc \& Jaume Torres I Estradé (2004) "Collamec-mecoll: estudi dels mots emprats en català per expressar el concepte de «dur una persona a les espatlles i/o l'esquena»", en Josep Massot i Muntaner (coord.), Estudis de llengua i literatura catalanes / XLIX. Miscel/lània Joan Veny, 5. Barcelona: Publicacions de I'Abadia de Montserrat, 201-231.

COROMINES, Joan \& José Antonio PASCUAL (2012) Diccionario crítico etimológico castellano e hispánico (DECH), edición en CD-ROM, Madrid: Gredos.

CORRALES, Cristóbal \& Dolores CoRbelLa Diccionario Histórico del Español de Canarias (DHECan) [http://web.frl.es/DHECan.html].

DAVIES, Mark (2002-) Corpus del español [https://www.corpusdelespanol.org/xs.asp].

FernÁNDEZ-ORdóÑEZ, Inés (dir.) (2005-) Corpus Oral y Sonoro del Español Rural (COSER) [http://www.corpusrural.es].

FERNÁNDEZ-ORDÓÑEZ, Inés (2007) “Nuevas perspectivas en el estudio de la variación dialectal del español: el Corpus Oral y Sonoro del Español Rural (COSER)", in D. Trotter (ed.), Actes du XXIV Congrès de Linguistique et Philologie Romanes, Tübingen: Niemeyer, vol. 3, 29-44.

GARCía ARIAS, Xose Lluis (2021) Diccionario General de la Lengua Asturiana (DGLA), Uviéu: Editorial Prensa Asturiana [https://mas.Ine.es/diccionario/].

GARCíA DE DIEGO, Vicente (1964) Etimologías españolas, Madrid: Aguilar.

García Mouton, Pilar (coord.), Inés Fernández-Ordóñez, David HeAP, Maria Pilar PereA, João SARAMAGO \& Xulio SOUSA, 2016, ALPI-CSIC [www.alpi.csic.es], edición digital de Tomás Navarro Tomás (dir.), Atlas Lingüístico de la Península Ibérica, Madrid: CSIC. 
Dialectologia. Special issue, IX (2021), 151-192.

ISSN: 2013-2247

García-PAge, Mario (2013) "Colocaciones léxicas con locuciones adverbiales integradas", in Antonio Pamies Bertrán (ed.), De lingüística, traducción y léxico-fraseología. Homenaje a Juan de Dios Luque Durán, Granada: Comares, 473-488.

GonzÁlez Cobas, Jacinto \& Ana SerRAdilla CASTAÑo (2013) “Unidades fraseológicas con verbos de movimiento. Propuestas para un diccionario", Círculo de Lingüística Aplicada a la Comunicación (CLAC), 54, 7-43.

LE Men LOYER, Jeannick (2019) Léxico del leonés actual (LLA), versión digital [http://cele.unileon.es/?page_id=104].

LLORENTE PINTO, María del Rosario (2005) "Léxico disponible y léxico dialectal en la provincia de Ávila", in Luis Santos Ríos (coord.), Palabra, norma, discurso: en memoria de Fernando Lázaro Carreter, Salamanca: Universidad de Salamanca, 681-694.

MAdRoñal DURÁN, Abraham (1986) "Vocabulario y toponimia de la jara toledana", Anales toledanos, 22, 211-252.

MARTí MAeSTRE, Joaquim (2012) "Afinidades léxicas aragonesas en el valenciano del siglo XIX", Archivo de Filología Aragonesa (AFA), 68, 143-176.

NEBOT CALPE, Natividad (1981) “Las voces naturales y la etimología popular en la toponimia y el habla del Alto Mijares y del Alto Palancia (Castellón)", Archivo de Filología Aragonesa (AFA), 28-29, 57-82.

ORTega OJedA, Gonzalo Damián \& María Isabel GonzÁlez AguiAR, 2005 “En torno a la variación de las unidades fraseológicas" en R. Almela, E. Ramón Trives \& G. Wotjak (eds.), Fraseología contrastiva (con ejemplos tomados del alemán, español, francés e italiano), Murcia: Universidad de Murcia, Universität Leipzig, 91-109.

PONS ROdRíguez, Lola (2020) El árbol de la lengua, Barcelona: Arpa.

ReAl ACAdemia EsPañola: Banco de datos (CORPES XXI) [en línea] Corpus del Español del Siglo XXI (CORPES) [http://www.rae.es].

ReAl ACAdemia Española: Diccionario de la lengua española, 23.a ed., [versión 23.3 en línea] [https://dle.rae.es].

ReAL ACADEMia ESPAÑola: Fichero General de la Lengua española (FG) [https://webfrl.rae.es/fichero.html].

SerRadilla CAStaño, Ana (2019) "Andando de zoca en colodra: las unidades fraseológicas con verbos de movimiento en la obra de Cervantes", Onomazein, 43, 181-199. 
SIMÓ, Leticia (2017) Los verbos andar e ir en el castellano del siglo XV en la Corona de Aragón: estudio semántico, funcional, cognitivo y contrastivo, Tesis doctoral, Barcelona: Universidad de Barcelona [https://tinyurl.com/y5lcke35].

TERRÓN VINAGRE, Natalia (2015) Variación léxica y semántica cognitiva: las designaciones de las actividades lúdicas en los atlas lingüísticos, Trabajo de fin de máster, Barcelona: Universitat Autònoma de Barcelona [https://tinyurl.com/yy3vgow5].

TIMOFEeVA, Larissa, 2008 Acerca de los aspectos traductológicos de la fraseología española, Tesis doctoral, Alicante: Universidad de Alicante [https://tinyurl.com/y5h8tj2x]. 